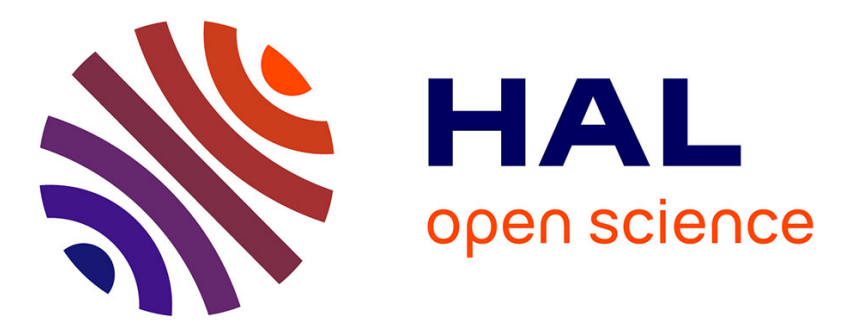

\title{
Electromagnetic modular Smart Surface architecture and control in a microfactory context
}

The Anh Tuan Dang, Magali Bosch-Mauchand, Neha Arora, Christine Prelle, Joanna Daaboul

\section{- To cite this version:}

The Anh Tuan Dang, Magali Bosch-Mauchand, Neha Arora, Christine Prelle, Joanna Daaboul. Electromagnetic modular Smart Surface architecture and control in a microfactory context. Computers in Industry, 2016, 81, pp.152-170. 10.1016/j.compind.2016.02.003 . hal-02120819

\section{HAL Id: hal-02120819 \\ https://hal.utc.fr/hal-02120819}

Submitted on 6 May 2019

HAL is a multi-disciplinary open access archive for the deposit and dissemination of scientific research documents, whether they are published or not. The documents may come from teaching and research institutions in France or abroad, or from public or private research centers.
L'archive ouverte pluridisciplinaire HAL, est destinée au dépôt et à la diffusion de documents scientifiques de niveau recherche, publiés ou non, émanant des établissements d'enseignement et de recherche français ou étrangers, des laboratoires publics ou privés. 


\title{
Electromagnetic modular Smart Surface architecture and control in a microfactory context
}

\author{
The Anh Tuan Dang*, Magali Bosch-Mauchand, Neha Arora, Christine Prelle, \\ Joanna Daaboul
}

Sorbonne universités, Université de technologie de Compiègne, CNRS, Laboratoire Roberval, Centre Pierre Guillaumat, CS60319, 60203 Compiègne Cedex, France

\section{A R T I C L E I N F O}

\section{Article history:}

Received 30 April 2015

Received in revised form 3 February 2016

Accepted 8 February 2016

Available online $\mathrm{xxx}$

Keywords:

Microfactory

Smart Surface

Reconfigurable manufacturing system

Flexible manufacturing system

Modular manufacturing system

Routing flexibility

Collision avoidance

\begin{abstract}
A B S T R A C T
This paper presents an electromagnetic conveyance system called electromagnetic modular Smart Surface (emSS) permitting to move pallets on a planar surface in a microfactory context. The proposed surface concept allows flexibility in reconfiguring the system layout along with product routing. The possibilities of accurate positioning of the moving pallet and controlling multiple pallets on the surface make the emSS suitable for reconfigurable and flexible manufacturing systems. However, the emSS control needs to be robust and scalable to adapt the changes in manufacturing systems. A framework is therefore defined to monitor and control the emSS by simulation or in-line. It allows to define product routing on the emSS by satisfying numerous requirements such as reduction in energy consumption, collision avoidance, etc., and to minimize the human interventions by changing product routing when emSS component failures occur. A first experiment realized on an emSS prototype, allowed to compare two paths strategies regarding cost function linked to energy consumption and velocities. Two other studies exploit the emSS modeling in terms of pallet path generation and simulation of collision avoidance.
\end{abstract}

\section{Contents}

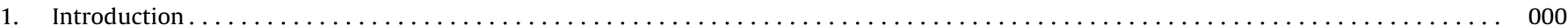

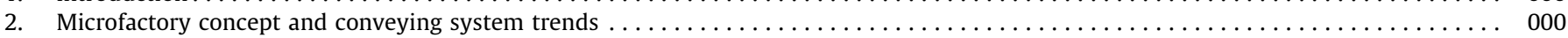

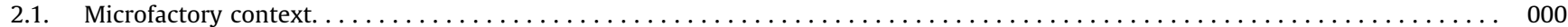

2.2. New trend for flexible and reconfigurable conveying systems: Modular microfactory and Smart Surface (SS) concept. ........ 000

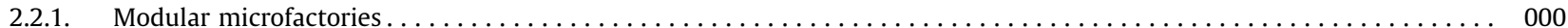

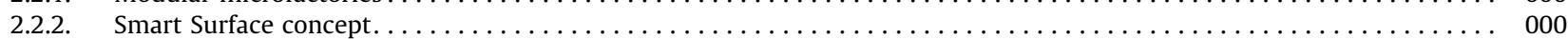

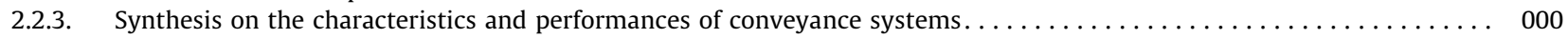

3. Proposed flexible transfer platform for microfactory: An electromagnetic modular Smart Surface . . . . . . . . . . . . . . . . . . . . . . 000

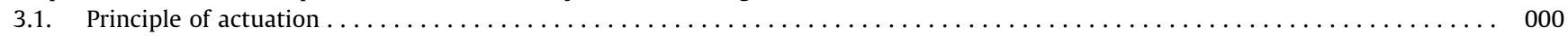

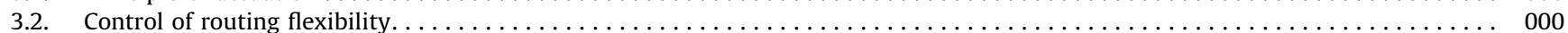

4. Proposed framework for the electromagnetic modular Smart Surface (emSS) management and control . .................. 000

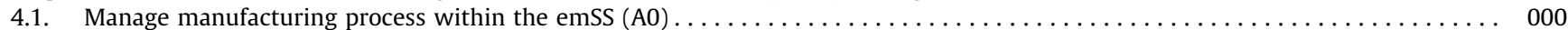

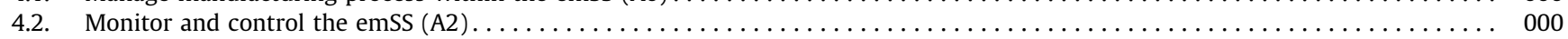

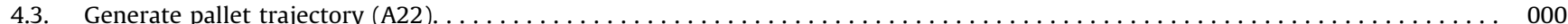

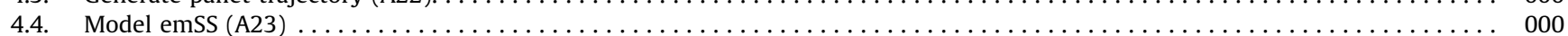

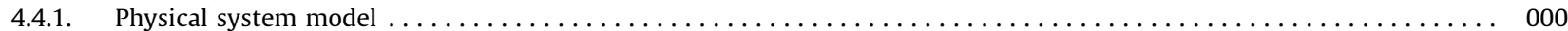

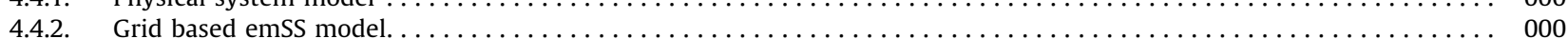

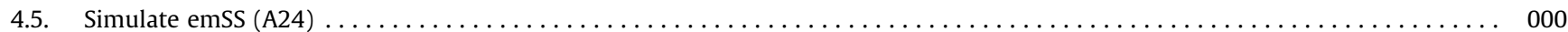

\footnotetext{
* Corresponding author. Tel.: +33 344237357.

E-mail address: the-anh-tuan.dang@utc.fr (T.A.T. Dang).
} 


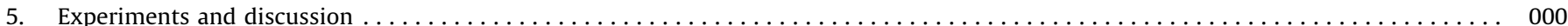

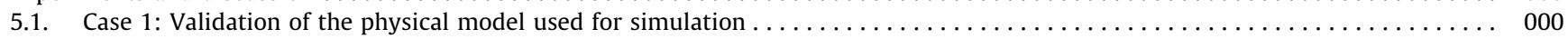

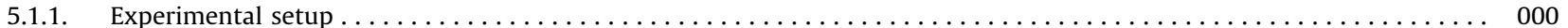

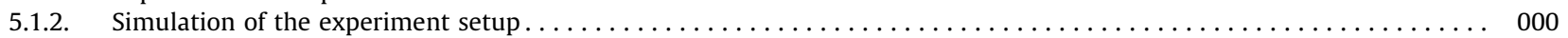

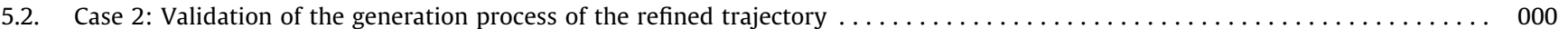

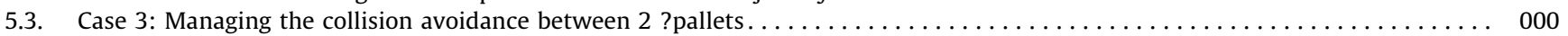

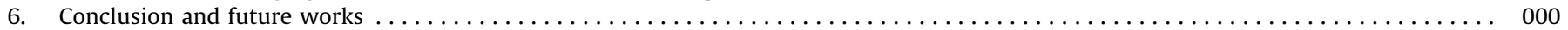

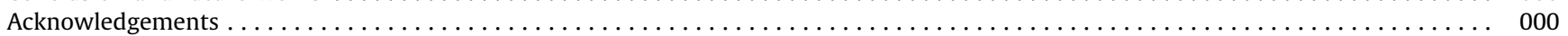

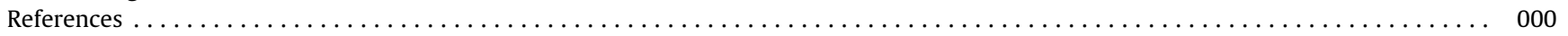

\section{Introduction}

Nowadays, micro manufacturing systems have been adopted as a new concept to handle numerous challenges linked to sustainability, globalization and increased competition [1-3]. In order to answer the turbulent business environment requirements [4], micro manufacturing systems are designed to be flexible and reconfigurable at both hardware and software levels $[5,6]$. In such a context, the microfactory concept has emerged and was first defined as a small manufacturing system in which production equipment is miniaturized to match product dimensions in order to reduce energy, material and space consumptions [7]. Furthermore, modular manufacturing systems architectures at machine level are applied for most of the microfactories currently developed. They provide flexible and reconfigurable manufacturing lines [3]. In such modular microfactory systems, each workstation is a modular item that is designed to work as a standalone unit or as a part of a production line [8]. With a standard interface, this workstation can be plugged at multiple locations in the microfactory and connected with others modular items. Thanks to exchangeable workstations, the microfactory can produce a wide range of products. Furthermore, Wang et al. have [9] demonstrated that the design of manufacturing systems based on the six RMS key requirements (customization, convertibility, scalability, modularity, integrability and diagnosability [10]) is more cost-effective and provides a better adaptability to market demands. For instances, the manufacturing capacity can be easily modified by adding, subtracting and/or changing modular items; the manufacturing system can be customized for a single product family.

At the same time, smart surfaces used to manipulate microobjects have been developed both on the technological point of view and on the control level $[11,12]$. Smart surfaces can be used as conveying system for microfactory $[13,14]$ and are defined as a set of identical modules, often distributed in a planar matrix layout [13], that can be rearranged in different 2D shapes. The goal of the presented work is to benefit from the Smart Surface concept and the modern modular manufacturing system design to achieve flexibility and reconfigurability requirements in microfactories. This paper focuses on the advantage of using an electromagnetic modular Smart Surface (emSS) to flexibly convey micro-products, located on pallets, over a planar surface. Hence, if production planning changes or perturbations occurrence implies a product routing modification, the pallet routing can be automatically reconfigured without the need of changing the production line. Therefore, the main research focus of the work presented in this paper is to propose a framework to control and monitor the emSS developed in the Roberval laboratory, and to perform first numerical and experimental tests to validate the physical model and the modules aiming to generate pallet path and simulate collision avoidance of this emSS.

This paper is organized as follows. First, microfactory concept is introduced; research works dealing with modular microfactories and smart surfaces are analyzed; and a synthesis is proposed related to requirements. Then physical principles and characteristics of the proposed emSS are described in Section 3. The proposed monitoring and control framework of the emSS enabling reconfigurability and flexibility is explained in Section 4. Finally, Section 5 describes three validation steps of the proposed framework. In the first step experimental results obtain with the real prototype are compared to simulation results in order to evaluate the coherency of the emSS physical model. The steps 2 and 3 are two numerical use cases, performed with this validated physical model, allowing to evaluate strategies for trajectories refining and for collision avoiding.

\section{Microfactory concept and conveying system trends}

\subsection{Microfactory context}

Earlier research works in microfactories have focused, on one hand, on downscaling manufacturing system components [7,15,16] (e.g.: miniaturized machine units and/or micro-press, small-size manipulator, transfer arm or conveyor system to transport the components, and small-size assembly unit or micro-manipulator to assemble the components) and, on the other hand, on integrating the microfactory components into a single portable box [17]. Then, the research interests related to microfactory have evolved to respond to flexibility requirements by developing modular concepts in order to organize the hardware part of the microfactory $[5,8,18]$. Now, the majority of the microfactories are designed at the outset for rapid change of the structure in terms of hardware as well as software components such as TUT microfactory [5,37]. The existing microfactories have demonstrated some benefits in saving investments, space, energy and resources. The next step is to enhance the performance of micro manufacturing systems such as the design of a fully automated systems with limited human tasks, as well as managing the emerging modular microfactories in order to insure flexibility in both routing and production [3,16,19].

Simultaneously, organization systems for data and information control have been developed to manage the microfactory according to different approaches found in the literature. For example, Fatikow et al. [20] and Gendreau et al. [21] have proposed a methodology to design modular control architecture adapted to micro modular manufacturing systems. In addition, Descourvières et al. [22] and Mauchand et al. [23] have defined data models to manage the reconfiguration of modular manufacturing layout. This means that in case of reorganization and reconfiguration, support functions such as product/process modeling, process planning, production and capacity planning, control of processes and production, and logistics have also to be adaptable and changeable $[24,25]$.

In the current context of mass-customization, where products have to be personalized to answer customer needs, modular manufacturing systems are a mean to improve industrial system flexibility by enabling a rapid change of production. Thus, in such a context of production change, material handling and product transfer processes have to be adapted (reconfigurable), and the 


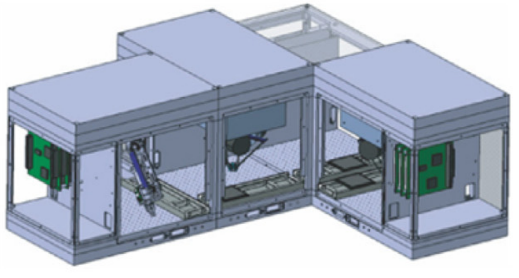

TUT microfactory [Heikkila et al. 2007]
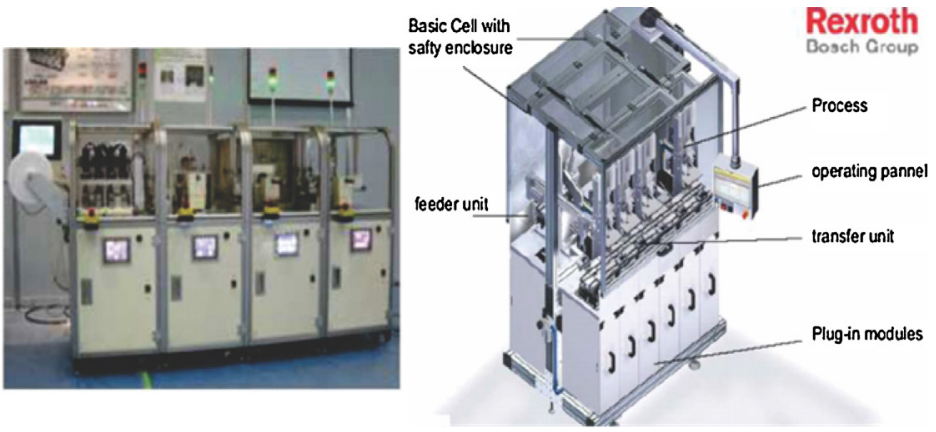

Module based microfactory AMRI \& new AIST Japon

[Nakano et al. 2008]
Bosch lean desktop factory [Klemd 2007]

Fig. 1. Example of modular microfactory with linear transfer line.

product trajectories within the microfactory must be flexible to produce multiple variants of one product.

\subsection{New trend for flexible and reconfigurable conveying systems: Modular microfactory and Smart Surface (SS) concept}

\subsubsection{Modular microfactories}

Existing modular microfactories can be classified into two categories based on their architecture for aggregating modules. In the first category, the modular microfactory is made of modular blocks including workstations and part of the transfer system as illustrated in Fig. 1. In the second category, machines and/or components can be plugged or removed near a flexible, but fixed, transfer system (planar surface) as shown in Fig. 2.

For product conveyance, the first category uses conventional downscaled linear transfer line split into independent elementary units that can be combined inside a module in order to setup the desired layout. The modular microfactory operating system is then composed of a set of several modules arranged side by side. The interfaces and setup as well as the geometry of such modules are standardized in order to guarantee smooth integration or exchange without costly time-intensive ramp-up. Thus, the modules can be freely and easily setup on different line layouts and the control of transfer units is relatively simple since it is predefined and linear. Furthermore, the linear transfer line allows high throughputs and accuracy of pallet positioning. However, in case of machine breakdown or full capacity, the entire production process is blocked. Therefore, in this type of modular microfactory, flexible and efficient production can by realized with "bypassing" conveyor that can be added to allow the carriers/pallets alternative routes [26]. Besides, in case of reconfiguration of the layout for a new process or a new product, manual intervention is required to adapt the layout, taking into account the predefined shape and orientation of each elementary transfer unit (in line, with corner, etc.).

The second category of modular microfactory is "flexible transfer line". In this case, the conveyance system is a planar surface on which a number of carriers or pallets can move independently and freely as shown in Fig. 2.

The carrier or pallet is defined as "active" when it is energized to power its own actuators and "passive" in the other cases. For this type of modular microfactories, modularity is due to the ability to plug or remove machines/stations anywhere around the conveyance systems according to the production need. This is achieved by using standardized interfaces. In this case, a base unit or table acts as a service module that supplies power, network connection, pressured air. . . to other connected modules. This concept provides routing flexibility and reduces time of layout reconfiguration. Nevertheless, this type of modular manufacturing system is limited to the dimension of the planar surface that is not adjustable such as AMMS [8] and Miniprod [27]. Moreover, in this type of system, the wired power supply of the carriers limits the area of displacement. Contrary to AMMS and Miniprod systems, the AAA system is built from a collection of modular base units, platen tiles, and bridges. The workstation modules are setup on the bridges at any locations. The aim of this system is to enable rapid deployment.

This second category responds to the flexibility requirements, nevertheless, the reconfigurability could be enhanced by increasing modularity of the planar surface.

\subsubsection{Smart Surface concept}

Up to our knowledge, there is no consensus in the literature on the concept of "Smart Surface" (SS) [13,28-30]. In the present

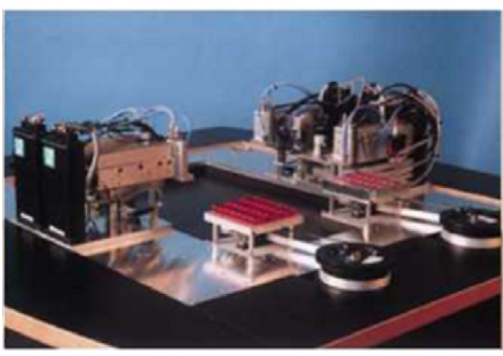

Advanced Modular Microassembly System (AMMS)

[Gaugel \& Dobler, 2002]

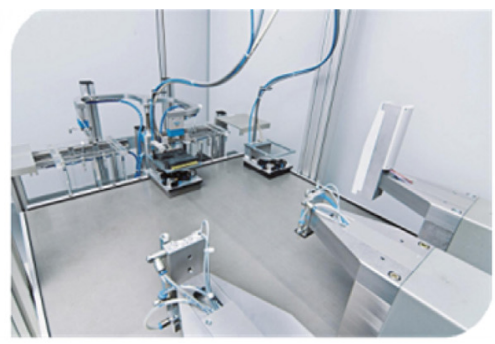

Miniprod

[Schmidt, 2005]

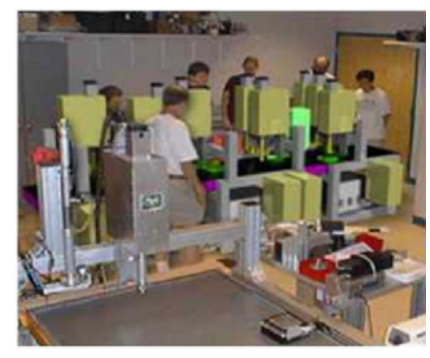

Agile Assembly Architecture (AAA) Carnegie Mellon University, USA [Rizzi et al., 2001]

Fig. 2. Example of modular microfactory with flexible transfer line. 


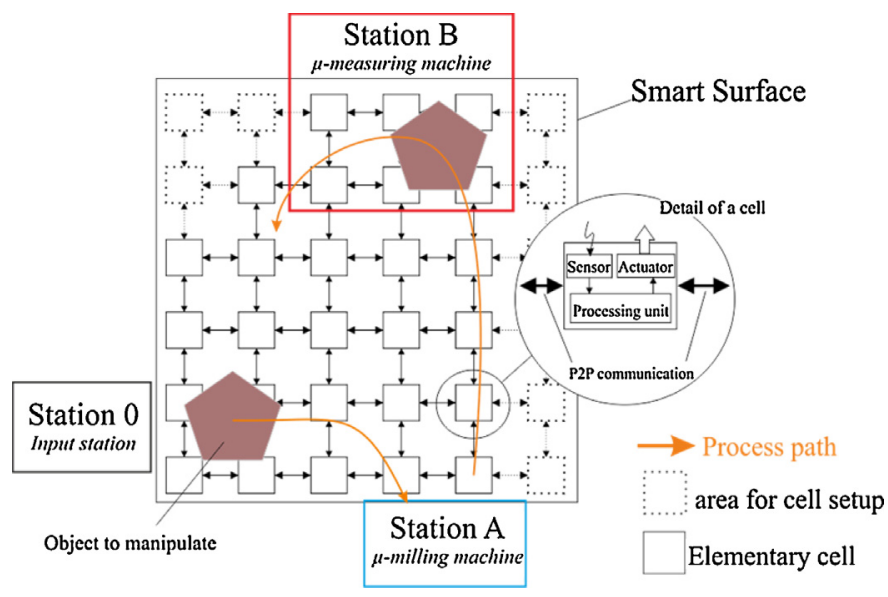

Fig. 3. Smart Surface concept in microfactory developed from [13].

paper, a "Smart Surface" or an "active surface" is defined as a micro conveyance system that can control the position of a micro object and allows its displacement within a planar surface in order to reach a desired position and orientation as shown in Fig. 3.

In Fig. 3 [13], a SS is based on a matrix of cells where each cell is composed of a micro actuator, a micro sensor and a processing unit. Indeed, by exploiting airflow [31], or electromagnetic $[29,30,32]$ principle, an array of massively parallel actuation cells can be successfully employed for micro conveyance of small objects. [31,32] showed that Smart Surface architectures are well adapted to flexible conveyance platform since it is possible to orientate and displace in parallel several objects or pallets that carry objects.

Yahiaoui et al. [12] recently showed the development of actuators array on a $9 \mathrm{~mm} \times 9 \mathrm{~mm}$ surface composed of $8 \times 8$ pneumatic micro-conveyors that can generate tilted air-jets in four directions. In the "Smart Block" project, a self-reconfigurable conveyor based on sliding blocks uses the pneumatic actuators described in [12] so that each block support arrayed actuators on its upper face. In [14], electro-permanent magnets are used to slide one block along another one in order to configure the conveyance system. In the future, the electro-permanent magnets will allow to automatically and easily reconfigure the surface in a new geometrical layout without the need of the human intervention.

Finally, the configuration of a SS can be set up as a linear or flexible transfer line or mixed, thanks to its design. On one hand, the matrix structure of the SS allows its scalability and modularity. On the other hand, the integration of functions such as recognition, conveyance and positioning increases the SS robustness.

\subsubsection{Synthesis on the characteristics and performances of conveyance systems}

From the previous sections, it is obvious that the conveyance system plays a significant role to enhanced flexibility or reconfigurability of microfactories. If a conveyance system reacts autonomously and immediately to changes (for instances: module breakdowns, as well as introduction of new modules, etc.) without crash, this can reduce the economic impacts in terms of logistic costs and delivery time. The capability to support dynamic workflow reconfiguration without shutdown the entire system appears as an important requirement in a flexible conveyor system. Therefore, specific criteria (e.g., flexibility, reconfigurability, pallet (carrier) type and workstation setup) have been chosen to identify the requirements for a better improvement of the conveying system concept.

Regarding flexibility, utilizing the possibilities of flexibly rerouting for alternative paths could enable avoiding interrupt production, rapid response to unexpected equipment failures or limit the human interventions for changing structure layout.

Regarding reconfigurability, the interface connecting the transfer units/modules have to be able to integrate modules rapidly and precisely. The microfactory design has to take into account the way to connect rapidly modules and to optimize the material flows through the microfactory.

A synthesis of the characteristics of existing conveyance systems according to the defined criteria is shown in Table 1. [18] has shown that the AAA system is flexible not only in that it deals with variability in the assembly process, but also that it can rapidly respond to changing market pressures. Contrary to others existing conveyance systems, SS seems to be comparable to AAA since both of them enable modularity, scalability, integrability, and customization.

As stated in [33], the next factories generation must be not only reconfigurable but also flexible. For that, conveying system should also be flexible and configurable for quick alternative process flow. The aim of recent researches is then to develop a modular conveyor that is then composed of a series of similar cells that can detect objects with sensors, move them with actuators and communicate with each other (such as SS) to form a flexible conveying path. Currently, all modular conveyors are connected to a base unit, which is an electronic control board that communicated with a host computer. A further idea is that the modular conveyor will be

Table 1

Conveyance system characteristics of existing modular microfactories.

\begin{tabular}{|c|c|c|c|c|c|c|}
\hline \multirow{2}{*}{$\begin{array}{l}\text { Conveyance } \\
\text { system type }\end{array}$} & \multirow[t]{2}{*}{ Concept } & \multirow[t]{2}{*}{ Flexibility } & \multicolumn{2}{|l|}{ Reconfigurability } & \multirow{2}{*}{$\begin{array}{l}\text { Pallet } \\
\text { type }\end{array}$} & \multirow{2}{*}{$\begin{array}{l}\text { Workstation } \\
\text { setup }\end{array}$} \\
\hline & & & $\begin{array}{l}\text { Integrability } \\
\text { (interfaces) }\end{array}$ & $\begin{array}{l}\text { Conveyor } \\
\text { structure }\end{array}$ & & \\
\hline \multirow{3}{*}{$\begin{array}{l}\text { Linear transfer } \\
\text { line see Fig. } 1\end{array}$} & TUT microfactory [37] & Line customized & Plug and play (module-module) & Adjustable modular & Passive & predefined \\
\hline & Bosch lean desktop [38] & Line customized & Plug and play (module-module) & Adjustable modular & Passive & predefined \\
\hline & $\begin{array}{l}\text { Module based } \\
\text { microfactory [39] }\end{array}$ & Line customized & Plug and play (module-module) & Adjustable modular & Passive & predefined \\
\hline \multirow{4}{*}{$\begin{array}{l}\text { Flexible transfer line } \\
\text { see Figs. } 2 \text { and } 3\end{array}$} & AMMS [8] & Routing & Plug and play (module-table) & Fixed & Active & fixed \\
\hline & Miniprod [27] & Routing & Plug and play (module-base unit) & fixed & Active & fixed \\
\hline & AAA $[40]$ & $\begin{array}{l}\text { Line customized, } \\
\text { Routing }\end{array}$ & Plug and play (module-base unit) & Adjustable modular & Active & predefined \\
\hline & Smart Surface [13] & $\begin{array}{l}\text { Line customized, } \\
\text { Routing }\end{array}$ & Plug and play (module-base unit) & Adjustable modular & Passive & predefined \\
\hline
\end{tabular}


able to self-reconfigure to form manufacturing line [14]. That means that a standard communication interface has to be developed for linking a modular conveyor to another. The purpose is to build a modular conveyance system that can transport items independently and simultaneously to different workstations, allowing different processes to be carried out on each item, and resulting in individually customized products.

The electromagnetic modular Smart Surface (emSS) based on conveyors developed by $[29,30]$ appears as a well-structured combination of modular conveyors and Smart Surface for modular microfactory. The research aims to design a modular conveyance system adapt to different transfer system requirements (e.g., positioning accuracy, rapidity, flexibility) and other applications (e.g., micro coordinate measuring machine) in such microfactories. Electromagnetic actuators combined with an active planar surface seem to be suitable for building light mobile modules. With passive pallets and matrix design, numerous layout configurations can be studied for best cost optimization.

\section{Proposed flexible transfer platform for microfactory: An electromagnetic modular Smart Surface}

In this section, an electromagnetic modular Smart Surface (emSS) is proposed based on previous works aiming to develop electromagnetic planar positioning systems [29,30,34].

\subsection{Principle of actuation}

Long time research works of the Roberval laboratory aim to develop electromagnetic planar positioning devices [34] and recently extend the concept to a conveyance platform including flexible planar electromagnetic conveyors $[29,30]$. The working principle of the electromagnetic conveyor system is based on
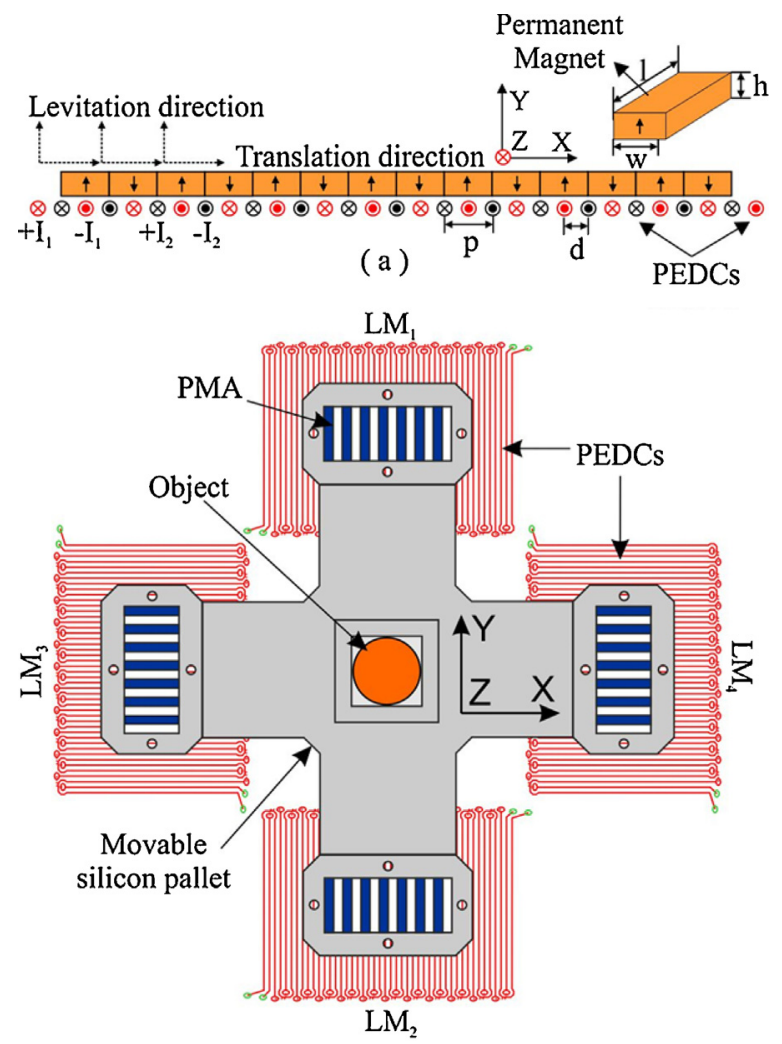

(b)

Fig. 4. Electromagnetic actuation principle (a) Single axis linear motor (b) 3DOF electromagnetic positioning device.
Lorentz force. As depicted in Fig. 4(a), when two sinusoidal currents, $I_{1}$ and $I_{2}$, with a relative phase shift of $\pi / 2$ are supplied to two fixed Planar Electric Drive Coils (PEDCs) placed underneath a Permanent Magnets Array (PMA), electromagnetic forces occur on the PMA, due to the interaction between the magnetic field from the PMAs and the currents in the coils, and generates the PMA motion [34]. Based on this principle, a 3 DOF $x y \theta$ positioning device has been developed which is capable of performing linear displacements along $x$ - and $y$-axis on a few millimeters stroke and a rotation $\theta$ along the axis perpendicular to the plane. The cross sectional view of a single axis Linear Motor (LM) is shown in Fig. 4 (a). The movable part consists of a silicon pallet designed in the form of a cross to integrate four PMAs arranged at the four edges of the structure [34,35]. Each PMA consists of 14 Permanent Magnets, each of dimensions $6 \mathrm{~mm} \times 1 \mathrm{~mm} \times 1 \mathrm{~mm}$ (see Fig. 4(b)). Two fixed PEDCs are placed underneath each PMA. Then the positioning device integrates four LMs where $\mathrm{LM}_{1}$ and $\mathrm{LM}_{2}$ are used for motion along $x$-axis while $\mathrm{LM}_{3}$ and $\mathrm{LM}_{4}$ are used for motion along $y$-axis.

In this positioning device, each PECD is dedicated to one PMA, forming a LM, and the stroke of each LM is limited due to the size of each PEDC (each PEDC is spatially separated from each other). In order to overcome this limitation, a two layer coils based design 2D actuator has been developed [29,30]. This new design uses two layers of coils: Layer 1 and Layer 2. The coils in Layer 1 and Layer 2 are overlapped and arranged orthogonally with respect to each other. With this new design, according to the relative position of the PMA in front of the coils, either a translation of the PMA along $x$-axis is realized supplying the coils of layers 1 , or a translation of the PMA along $y$-axis is performed supplying the coils of layer 2 (see Fig. 5). With this coil design, the displacement stroke can be increased in proportion to length of the coils. Nevertheless, the stroke increase implies an increase on the coils resistance and then an increase of energy consumption.

Therefore, the two layer principle is further extended to develop a long range electromagnetic conveyor system based on a matrix design. Each cell of the matrix is made of overlapped and orthogonally arranged 2D coils as previously described.

Each elementary cell of the matrix can be managed and controlled independently by activating the required coils depending on the position of the pallet. In the same manner as for the previous stage, for displacement of the silicon pallet along $x$-axis, two opposite $\mathrm{LMs}\left(\mathrm{LM}_{1}\right.$ and $\left.\mathrm{LM}_{2}\right)$ in Layer 1 , are supplied simultaneously with currents (see Fig. 6(a)). In the same way, $\mathrm{LM}_{3}$ and $\mathrm{LM}_{4}$ in Layer 2 are supplied with currents at the same time to perform motion along $y$-axis (see Fig. 6(b)). All the four LMs $\left(\mathrm{LM}_{1}, \mathrm{LM}_{2}, \mathrm{LM}_{3}\right.$ and $\left.\mathrm{LM}_{4}\right)$ are supplied independently in order to perform planar motions (see Fig. 6(c)). That means, at each instant and for a given position of the mobile part, specific cells of the matrix are required to be activated in order to generate motion while the remaining cells are no more activated. This strongly reduces the electrical resistance of the activated coils and thus, energy consumption is low especially over large surfaces. Besides, the matrix design configuration ensures the possibility of controlling and managing several pallets at the same time without any manual intervention.

Moreover, the emSS is designed to be suitable for reconfigurable manufacturing system paradigm [10] as argued in Table 2 and Section 2.2.3.

\subsection{Control of routing flexibility}

In order to analyze the emSS control, an example of manufacturing a gear is considered (Fig. 7). A raw material block is placed above the pallet at the input station (Station 0 ). The first task is machining, realized by the milling machine located at Station $A$. The pallet is hence transferred to Station $A$ through path 
T.A.T. Dang et al./Computers in Industry $x x x$ (2016) $x x x-x x x$

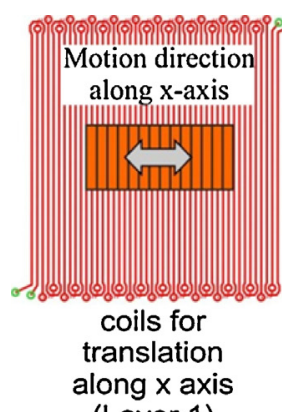

(Layer 1)
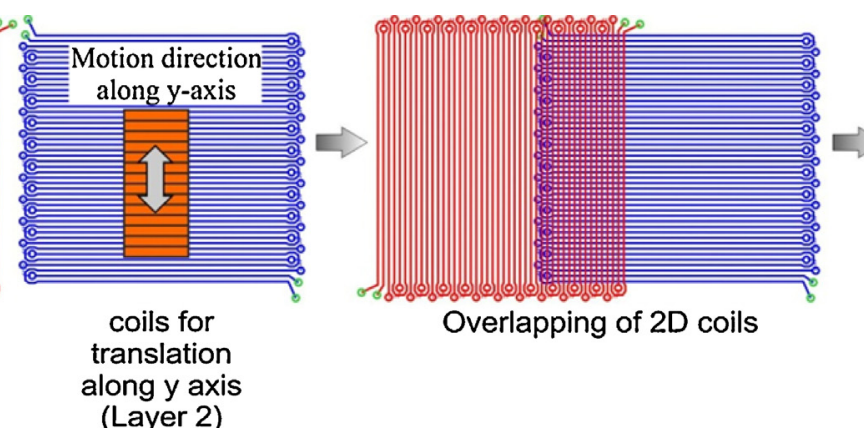

Overlapping of 2D coils

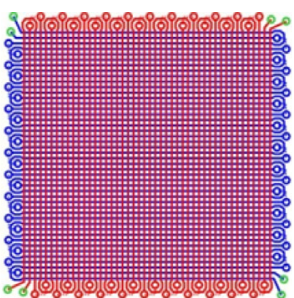

Two layer coil design (elementary cell)

Fig. 5. Two layer coils based 2D actuator.

Coils in Layer 1 are activated

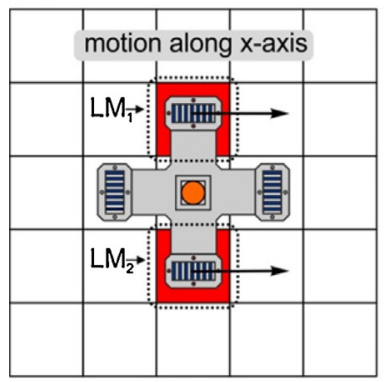

(a)
Coils in Layer 2 are activated

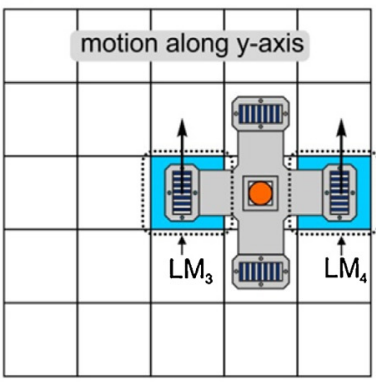

(b)
Elementary cell of the matrix

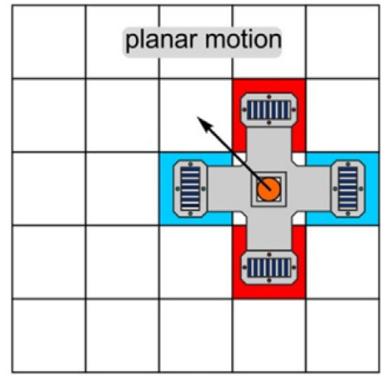

(c)

Fig. 6. Working principle of the conveyance platform.

Table 2

RMS characteristics enabled by the electromagnetic modular Smart Surface.

\begin{tabular}{|c|c|c|c|c|c|c|}
\hline \multirow[t]{2}{*}{ Flexibility } & \multirow[t]{2}{*}{ Convertibility } & \multirow[t]{2}{*}{ Diagnosability } & \multicolumn{2}{|l|}{ Reconfigurability } & \multirow{2}{*}{$\begin{array}{l}\text { Pallet } \\
\text { type }\end{array}$} & \multirow{2}{*}{$\begin{array}{l}\text { Workstation } \\
\text { setup }\end{array}$} \\
\hline & & & Integrability (interfaces) & Conveyor structure & & \\
\hline $\begin{array}{l}\text { Line customized, } \\
\text { routing }\end{array}$ & $\begin{array}{l}\text { Linear or/and flexible } \\
\text { transfer line }\end{array}$ & $\begin{array}{l}\text { Detection of cell } \\
\text { failure and } \\
\text { path redefinition }\end{array}$ & $\begin{array}{l}\text { Plug and play (module-base unit), } \\
\text { distributed control, information } \\
\text { system modules }\end{array}$ & $\begin{array}{l}\text { Adjustable } \\
\text { modular }\end{array}$ & Passive & Predefined \\
\hline
\end{tabular}

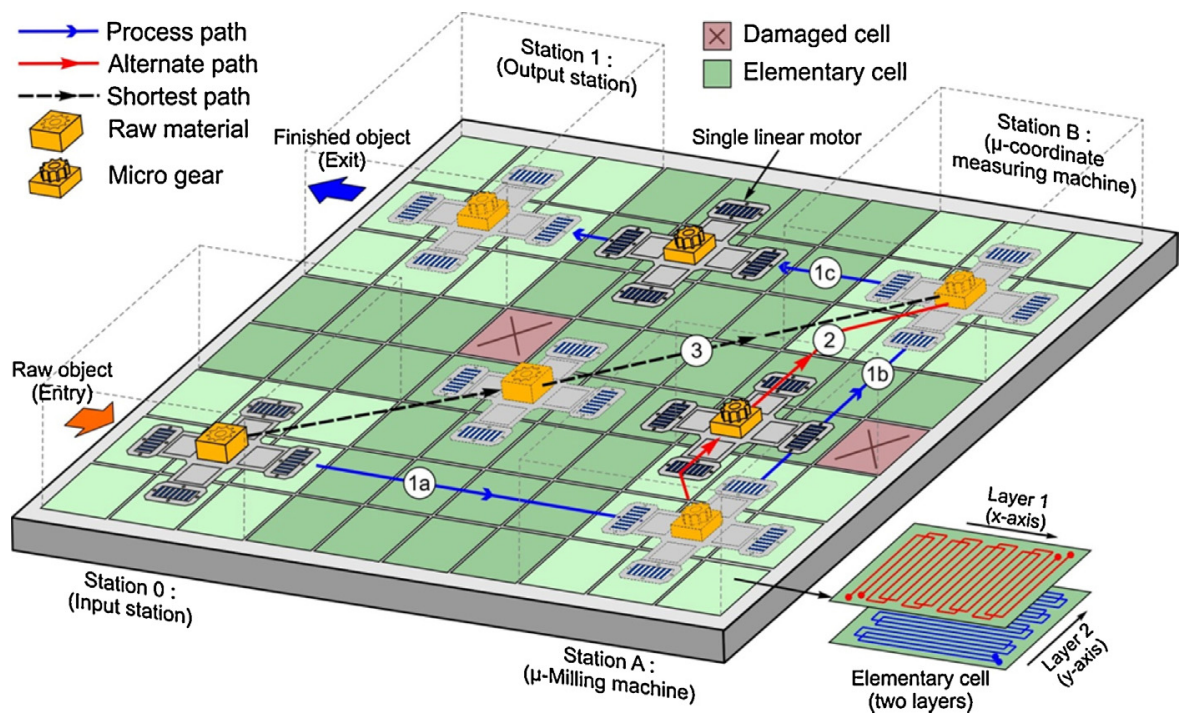

Fig. 7. Flexible electromagnetic conveyor platform [Arora 2014]. 
(1a). The machined gear is geometrically controlled by a micro measuring machine located at Station $B$. The pallet is transferred to Station $B$ through path (1b). Then the final product is sent to the output station at Station 1 following path (1c). Therefore, the overall process path to be followed is $(1 \mathrm{a}) \rightarrow(1 \mathrm{~b}) \rightarrow(1 \mathrm{c})$. The shortest path (3) $\rightarrow$ (1c) can be followed if only measurement task has to be performed. Using this shortest path in required manufacturing plan saves energy and time to finish the process. Moreover, if damaged cell makes it impossible to use path (1b) then an alternative path $(1 \mathrm{a}) \rightarrow(2) \rightarrow$ (1c) can be followed for the smooth functioning of the process. The whole process can be thus continuously realized without any manual intervention.

This example illustrates the need of a framework to monitor and control the pallet routes within the emSS. In particular, the framework needs to coordinate the pallets activities on the platform, to handle unpredicted constraints such as cells failure, and to manage complex trajectories. To ensure the scalability, flexibility and reconfigurability requirements of the emSS, the framework must include the following functionalities:

- Easily add, modify, erase an object (a cell, a pallet, a product, etc.) in the database;

- Allow users to design the emSS via a graphical representation;

- Update the database concerning the changes in the layout of the emSS after reconfiguration;

- Identify cell failures, and recalculate the optimal pallet's route if needed;

- Evaluate and optimize the virtual preconfigured platform to reduce engineering costs.

The main issues arising from satisfying these functionalities are:

- Having an extendable database, and based on it a module allowing reconfiguration of the platform taking into consideration changes in the number of available cells;

- The need for accurate and real time communication between the physical platform and the control system;

- The recalculation time of a new route should be faster than the pallet displacement;

- Taking into consideration the routes of all pallets to avoid collision.

\section{Proposed framework for the electromagnetic modular Smart Surface (emSS) management and control}

In this section, and in order to answer the issues identified above, a novel framework to achieve the emSS management and control is presented. This consists of:
- communication with Enterprise Resource Planning (ERP), in order to receive the production plan;

- layout definition and reconfiguration due to: cells modifications (added or deleted cells), new products (hence new production line);

- pallets monitoring and path optimization to generate pallet trajectory;

- data exchange for emSS control.

\subsection{Manage manufacturing process within the emSS (A0)}

Within an industrial company, the production process planning is usually managed by the ERP. In the activity A1-Schedule production (see Fig. 8), the production planning is proposed by ERP and can be modified by the production supervisor when there are inventory adjustments, scrapped parts, lost parts or priority orders.

This production planning together with the emSS layout are considered as the inputs to monitor and control the emSS taking into account specific objectives like defining the shortest paths, the least energy consumption, or avoiding collision. An application called the Monitoring \& Control Software (MCSo) has been developed to manage and supervise the monitoring and control of the pallets activity within the emSS via a user-friendly interface. The next section focuses on functionalities associated with the monitoring and control of the emsS.

\subsection{Monitor and control the emSS (A2)}

The monitoring and control activity is structured into four tasks: update database, generate pallet trajectory, model and simulate the emSS (Fig. 9).

Through the activity A21-Update database, the database collects the production planning (operation/workstation sequences) and layout definition (emSS dimension and shape; cells size and state; workstations footprint, dimension and location; pallet characteristics...). A class for each type of objects such as pallet, cell and workstation is defined with their attributes such as the identity Id and the state. This state attribute can be active, inactive or defected. The database is automatically or manually updated in case of reconfiguration or after maintenance intervention (Fig. 9).

Taking into account database information and objectives such as production time, energy consumption and collision avoidance, the displacement of each pallet is generated and optimized with activity A22-Generate pallet trajectory by MSCo_algorithms and MSCo_collision detection modules (explained in details in Section

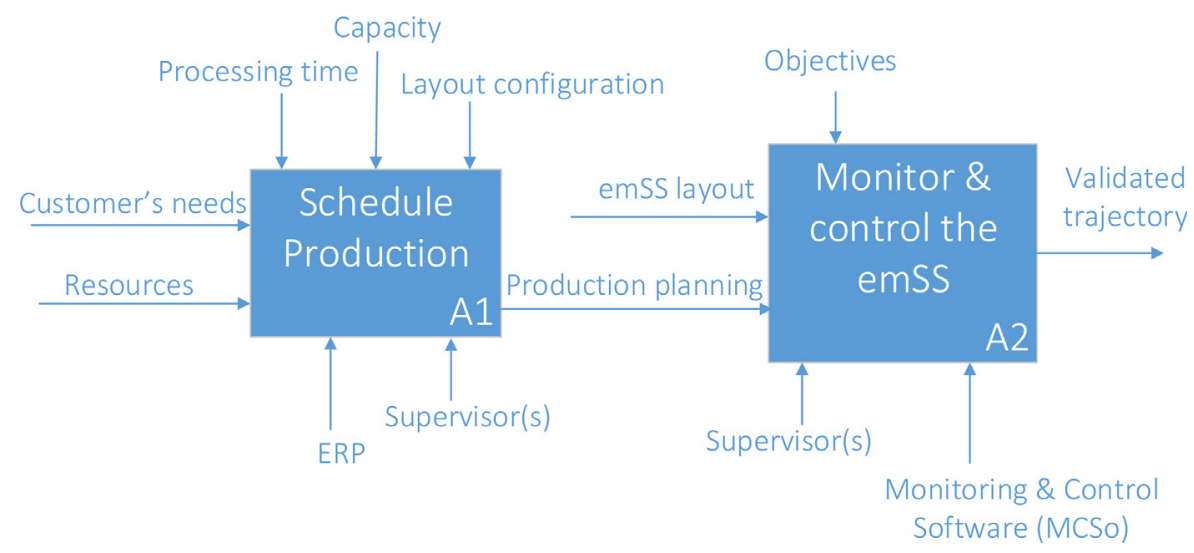

Fig. 8. IDEFO AO Manage transfer process within the emSS. 


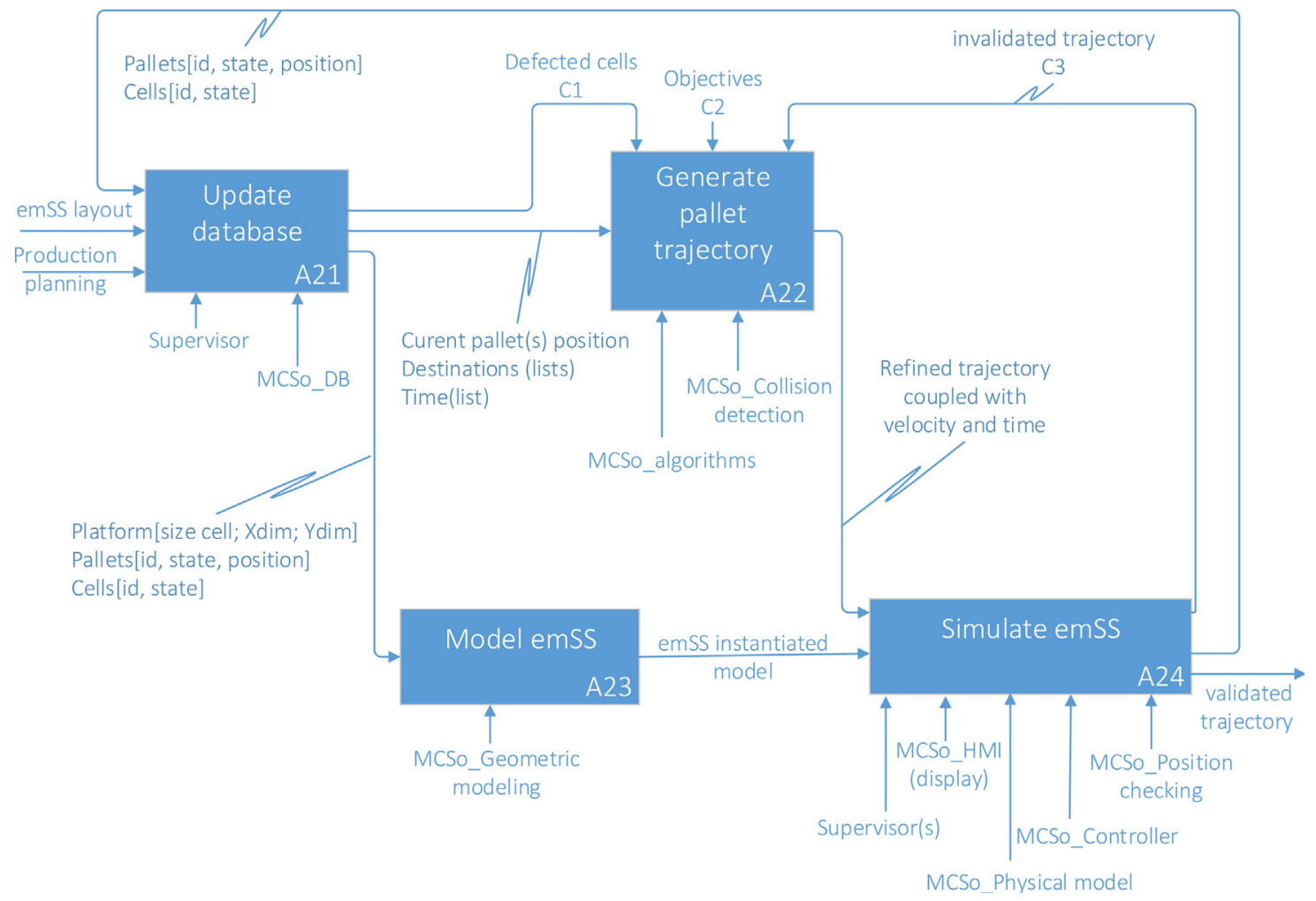

Fig. 9. IDEFO A2 Monitor \& control of the emSS.

4.3). Taking into account database information and geometric model, the activity A23-Model emSS (explained in details in Section 4.4), defines the emSS instantiated model (location and state of the cells, workstations and pallets).

This emSS instantiated model and the defined trajectories are simulated in the activity A24-Simulate the emSS (explained in details in Section 4.5), by including physical model. The resulting refined trajectories can be validated or invalidated. In this last case, the invalidated trajectories are eliminated for the next calculation step of the pallet trajectory.

\subsection{Generate pallet trajectory (A22)}

The generate pallet trajectory activity is executed following a workflow as shown in Fig. 10.
In order to control the pallet path from its current position to its destination (Fig. 11, stage 1), the first step A221 aims to define the pallet raw trajectory as a set of via points (located at cell centers) taking into account the objectives (Energy consumption/shortest path) and the defected cells as avoided cells (Fig. 11, stage 2 ). At the second step, the calculation of pallet paths is considered as a graph path-planning problem. The activity A222-Interpolate trajectory with different methods, refines the raw trajectory in order to obtain a smooth desired trajectory with interpolated points. Different interpolation functions can be compared (spline, Beziers, etc.) and chosen (Fig. 11, stages 3 ). The refined trajectories of each pallet are then used in the activity A223 to find the intersection points between a pallet and others (Fig. 11, stages 4 ). In the activity A223-Choose trajectory and define velocity, the input is filtered by eliminating the invalidated trajectory $\mathrm{C} 3$ that is defined in the

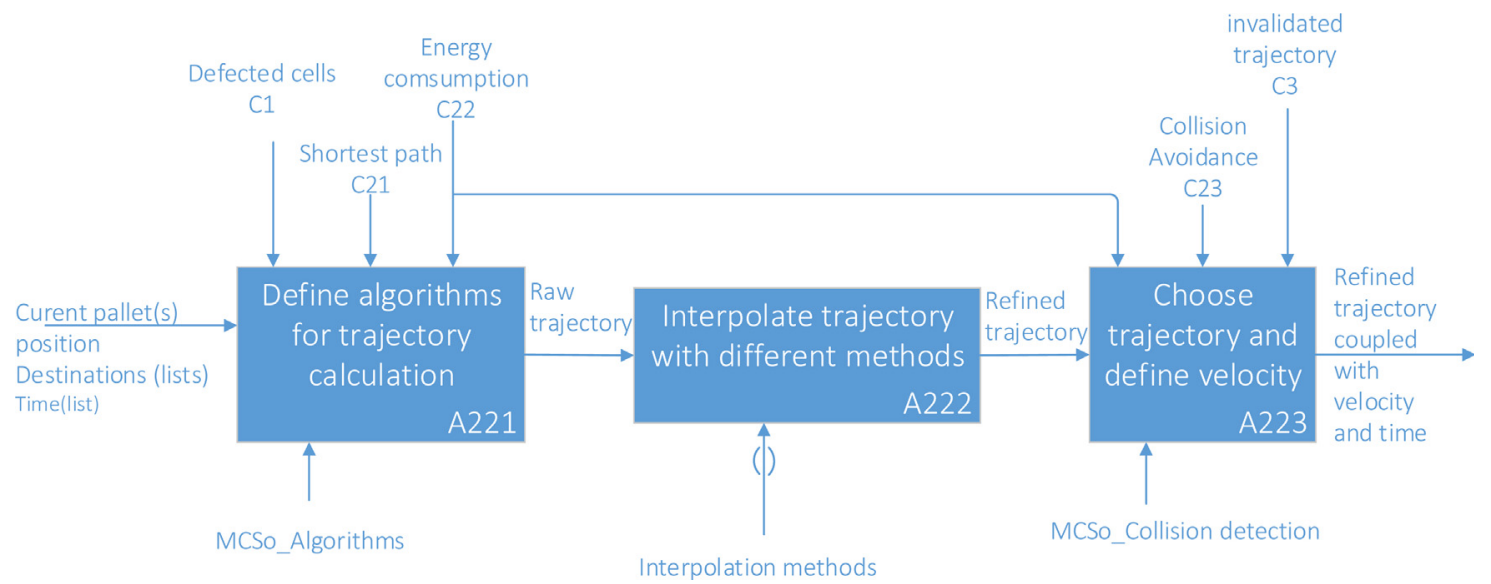

Fig. 10. IDEFO A22 Generate pallet trajectory. 


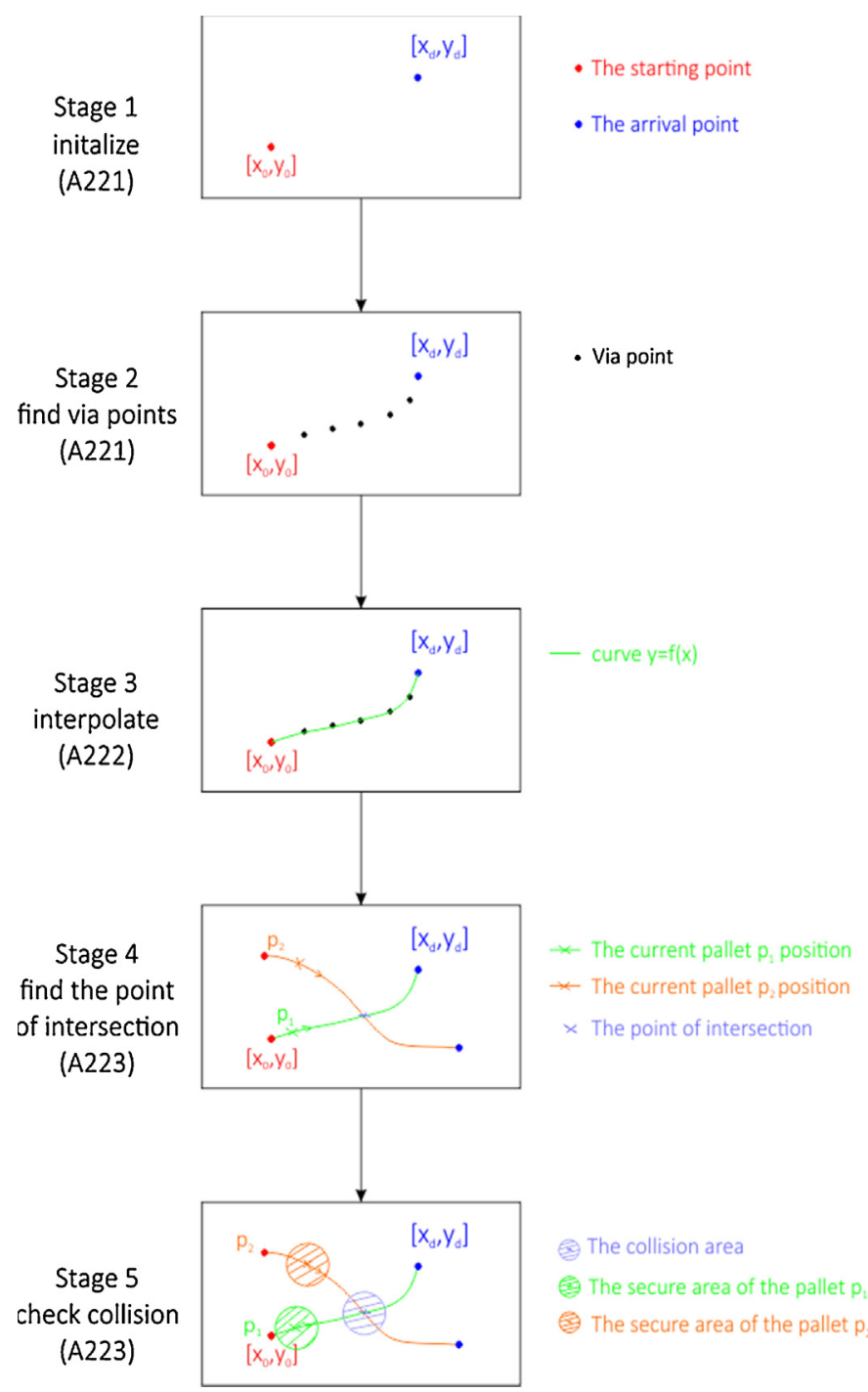

Fig. 11. The activities from calculating trajectory to checking collisions.

activity A24-Simulate emSS. The "MCSo_Collision detection" module is used to detect the possibility of collision between two pallets and disqualify the undesirable trajectories before validating the final trajectory (Fig. 11, stages 5). This module is also used to detect in real time the collision. In the case of a possible intersection, this module could take decisions on the pallet control (for instances: varying the velocity of the pallet, respecting the due date and the priority of one product order).

\subsection{Model emSS (A23)}

In this section, the modeling of the emSS is defined in details to give the assumptions and the model characteristics (corresponding to the activity A23 in Fig. 9). In a second time, the grid based emSS representation principle is explained.

\subsubsection{Physical system model}

The emSS modeling is divided into 2 stages as follows:

- The Lorentz force analytical and mechanical models:

Knowing that the electromagnetic force, which is the result of the interaction between magnetic flux density from the PMA and currents in the PEDCs, depends on the number of turns in a coil of the PEDC below the PMA, this force will immediately drop when a pallet passes over the transition zone because of the absence of coils (as shown in Fig. 12 and see Section 3.1) between two cells. In this case, the mathematical model needs to take into account this effect. The dimension of the transition zones is designed to have a fixed number of the pair of turn coils for ensuring the continuous motion of a pallet. A matrix I denotes the current sent to the emSS cell. The dimension of the matrix $I_{x}$ for the $x$ direction and the matrix $I_{y}$ for the $y$ direction includes the number of turn coils of all the PEDC and the ones of transition zones for each direction. The magnitude of sinusoidal currents injected into the turn coils at the transition zone equals $0 A$. The maximum allowable magnitude of the sinusoidal currents injected into coils is $0.8 \mathrm{~A}$. The friction and adhesion forces in the translation of the mobile part involve the final computing force due to the total net weight of pallet while transporting products or items.

- The graphical model

The "MCSo_Geometric modeling" module is written in Matlab/Simulink for modelling the emSS and the pallets. The current layout model will be updated and displayed by the "MCSo_HMI".

\subsubsection{Grid based emSS model}

Due to the emSS layout, a 2D grid based model is applied. The model is binary (each grid cell contains either an obstacle like the footprint of workstations, etc. or free space) and associates to each cell a cost reflecting the difficulty of moving a pallet from it to its neighbor cells. For resolving the problem of finding the shortest
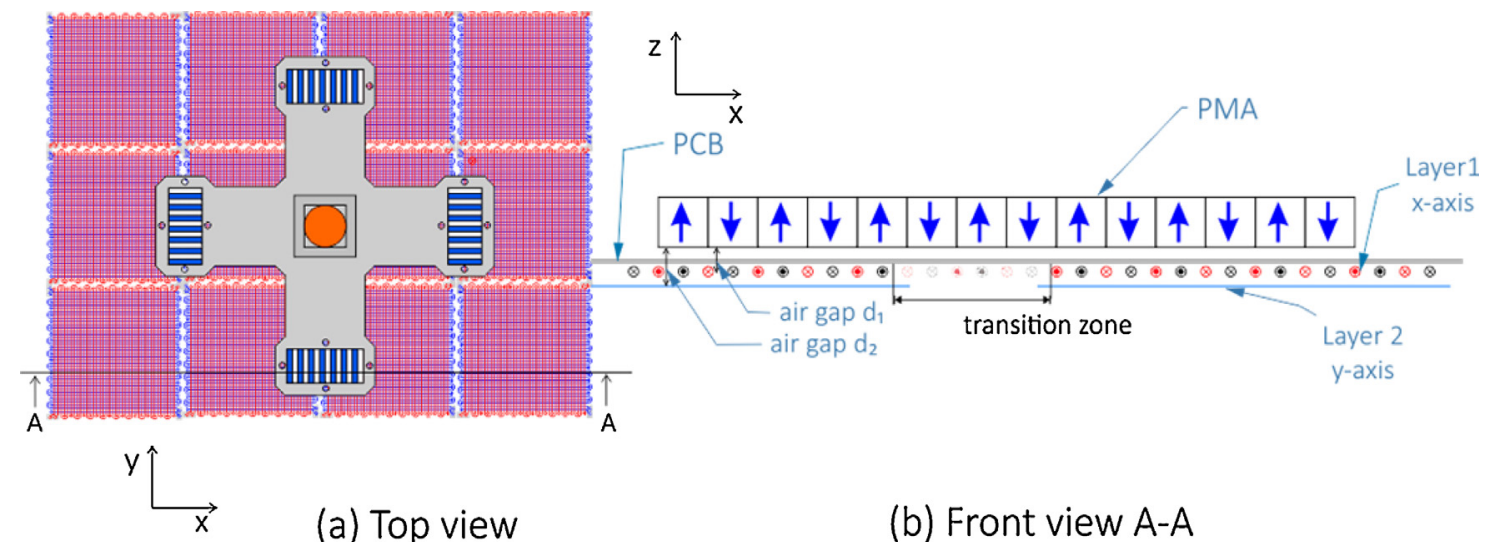

(a) Top view

(b) Front view A-A

Fig. 12. Pallet at the transition position. 


\begin{tabular}{|c|c|c|c|c|}
\hline 21 & 22 & 23 & 24 & 25 \\
\hline 16 & 17 & 18 & 19 & 20 \\
\hline 11 & 12 & 13 & 14 & 15 \\
\hline 6 & 7 & 8 & 9 & 10 \\
\hline 1 & 2 & 3 & 4 & 5 \\
\hline
\end{tabular}

A : square shaped layout $(\operatorname{dim} X=5$ cells) many to many type

\begin{tabular}{|c|c|c|c|c|c|c|c|c|c|}
\hline 41 & 42 & 43 & 44 & & (6) & 12 & 48 & 49 & 50 \\
\hline 31 & 32 & 33 & 34 & & 38 & 372 & 38 & 39 & 40 \\
\hline 21 & 22 & 23 & 24 & 25 & 26 & 27 & 28 & 29 & 30 \\
\hline 11 & 12 & 13 & 14 & 15 & 16 & 17 & 18 & 19 & 20 \\
\hline 1 & 2 & 3 & 4 & 5 & 6 & 7 & 8 & 9 & 10 \\
\hline
\end{tabular}

hybrid type

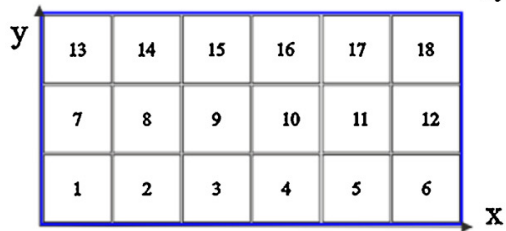

$\mathrm{B}$ : rectangle shaped layout (dim $X=6 \mathrm{cell} s)$ one to one type

Fig. 13. Different platform shapes with indexed cells.

path, this grid is converted into a graph in which each node of the graph denotes the cell center coordinates. The cost value for moving one cell to its neighbors represents the link of the graph. Many algorithms exist for graph shortest path identification like Dijkstra's algorithm, A*, Floyd-Warshall algorithm, etc. [36]. Those algorithms are used to find the appropriate solution.

To simplify the calculation, the index of a cell in the emSS matrix represents its identity attribute in the MCSo database. There, the emSS is modeled by a uniform grid data structure and its cells are indexed as shown in Fig. 13. In order to be adapted to all emSS layouts, the emSS matrix is defined as a square matrix of order $\mathrm{n}$ where $\mathrm{n}$ is the maximal value between the number of cells in the $x$ direction and in the $y$ direction (see Fig. 13). The zone without cells is represented as defected cells in the emSS matrix and these cells have their own identity. The index system is automatically recalculated when the layout is modified.

\subsection{Simulate emSS (A24)}

The emSS simulation activity includes the simulation of cells state (A242) and the pallet displacement (A243) as detailed in Fig. 14.

In the activity A241-Generate cells control, the "MCSo_controller" module is used to convert the input parameters to cell control (current matrix). Each pallet needs at least one or two pair of cells for moving in one direction and it only works if cells are active and power. For precise positioning, the frequency $\omega$ of the injected sinusoidal currents $I_{1}$ and $I_{2}$ in the cells is adjusted in

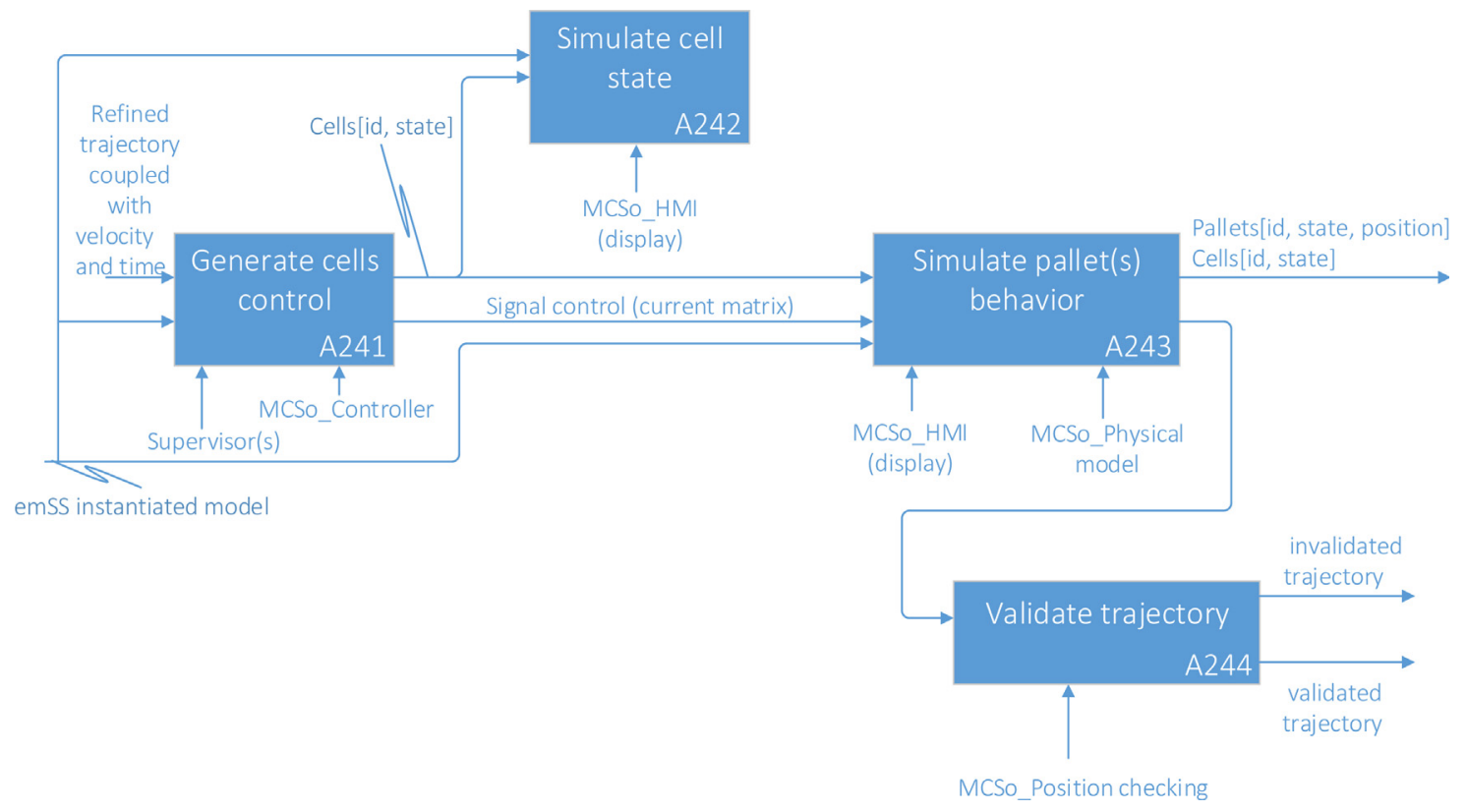

Fig. 14. IDEF0 A24 Simulate emSS. 
the $x$ direction

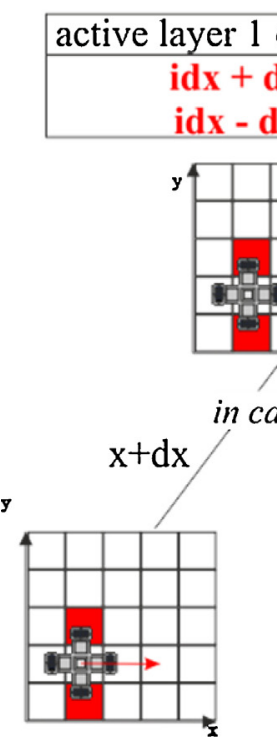

the $y$ direction

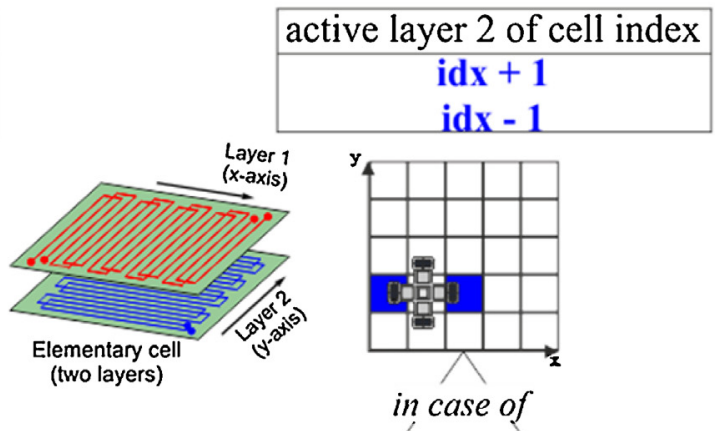

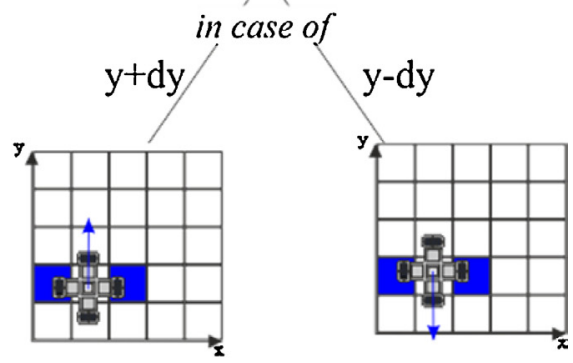

Fig. 15. A pallet control.

function of travel time and the distance between the current position and the destination.

The activity A242-Simulation cell state defines cells layer states in the "MCSo_HMI" module as follows:

- Active state when currents are sent to cell. Each layer cell has its own state (the red color for the $x$ direction and the blue color for the $y$ direction as shown in Fig. 15);

- Inactive state;

- Defected state when cell is defected or occupied.

"MCSo_HMI" also displays the form and dimension of the emSS and the pallets given by the activity A23 at each time step of simulation. When the currents are sent to the cell, the "MCSo_Physical model" module that is implemented inside the activity A243, is used to calculate the electromagnetic forces applied to the pallets. Since the emSS is a matrix of cells, two matrix of cell states are needed for modeling the two layers of emSS as shown in Fig. 15. The idx, dimX denote the index of a cell in the square matrix and the number of cells in the $\mathrm{x}$ axis, respectively.

In order to control simultaneously several pallets, the control signal is defined as a combined matrix. For each step time of simulation, the pallet position and cell state are sent to the database for monitoring the pallet along its trajectory.

The activity A244 is used to select the validated trajectories that respect the imposed travel time. Simulating the dynamic behavior of emSS and its control system allows us to study and to choose the appropriate trajectory for each pallet.
The "MCSo_Position checking" module has the function to control and check the pallet position during the simulation. Due to some control limitations, the pallet can be located in a zone (for instances: transition zone, and so on) where it is impossible for pallet to leave. In this case, the "MCSo_Position checking" module will take decision to stop the pallet simulation and state the invalid trajectory to the activity A22.

Supervisor can always take the control of one pallet by changing the control mode (from manual mode to automatic mode).

\section{Experiments and discussion}

In order to justify the workflow in the activities A22, A23 and A24, three study cases are presented. It allows not only to compare the simulation results with the first experimental setup but also to improve the layout design and pallet control in the future. Hereafter, different cases will be presented to validate the different control functionalities.

\subsection{Case 1: Validation of the physical model used for simulation}

In this study case, an experiment is setup to compare the experimental results with simulation results and to allow control and observation of the behavior of the emSS when a pallet cross over the transition zone. This aims to validate the emSS physical model defined for simulation purposes.

In simulation, some relevant characteristics are taken into account:

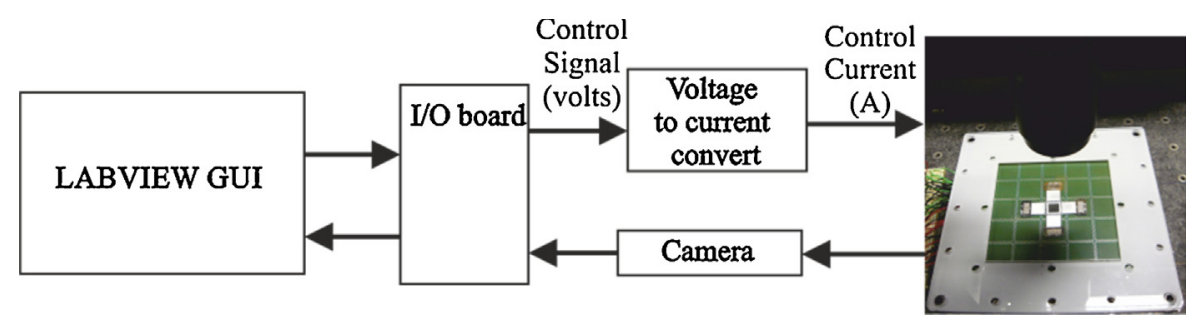

Fig. 16. Experimental setup. 
- a high current may damage the coils or degrade the residual magnetization of the PMAs;

- the air gap between the mobile and coil in the layer 2 is bigger than the air gap between the mobile and coil in the layer 1 as show in Fig. 12;

- the unbalance of electromagnetic forces applied on the two extremities of a pallet at certain areas introduces the rotation of the pallet;

\subsubsection{Experimental setup}

The experimental setup shown in Fig. 16 has been realized in order to validate the emSS modeling.

In order to validate the emSS model, a prototype of the emSS formed of a $5 \times 5$ square matrix has been developed. The overall surface dimensions of the conveyor platform are $130 \mathrm{~mm} \times 130 \mathrm{~mm}$. The thickness of copper of the coils in each layer is $35 \mu \mathrm{m}$. The distance between the two layers is $282 \mu \mathrm{m}$. A $130 \mu \mathrm{m}$ thick glass layer has been glued to the bottom side of the PMA support structure. This glass layer is used to achieve smooth motion of the pallet over the emSS and to prevent direct contact between the current carrying coils and magnets that helps to minimize the friction. Therefore, the air gap $d_{1}$ and $d_{2}$ (as shown in Fig. 12) are respectively $130 \mu \mathrm{m}$ and $447 \mu \mathrm{m}$. The total weight of the pallet is $3.7 \mathrm{~g}$ and the adhesion coefficient $\mu_{\text {adhesion }}$ between the glass layer and the PCB surface equals 0.23 .

A computer equipped with a data acquisition board (NI PCI6733 ) with a LABVIEW interface is used to generate two controlling voltages for each axis. These voltages are then converted into currents using voltage to current converters. The voltage input and current output of both the converters are in the range of $[-10 \mathrm{~V}$, $10 \mathrm{~V}]$ and $[-3 A, 3 A]$ with a bandwidth of $50 \mathrm{kHz}$. For the displacement measurement, a camera has been fixed above the emSS in order to obtain images of pallet while moving. The images of size $1024 \times 768$ pixels have been captured by the camera.

Currents needed for the motions along $y$-axis are higher than the ones used for motions along $x$-axis due to the larger distance between the PMAs and Layer 2 in order to equal forces generated during the motion along both axes and obtain similar motion characteristics. The relation between these two currents is given in the following equation [29,30]:

$I_{x}=0.53 \times I_{y}$

An experiment has been carried out to show the ability of the experimental emSS to perform long stroke displacements by crossing several cells and also to determine the velocity in the $x$ and $y$ direction via decoupled or coupled displacement. In order to

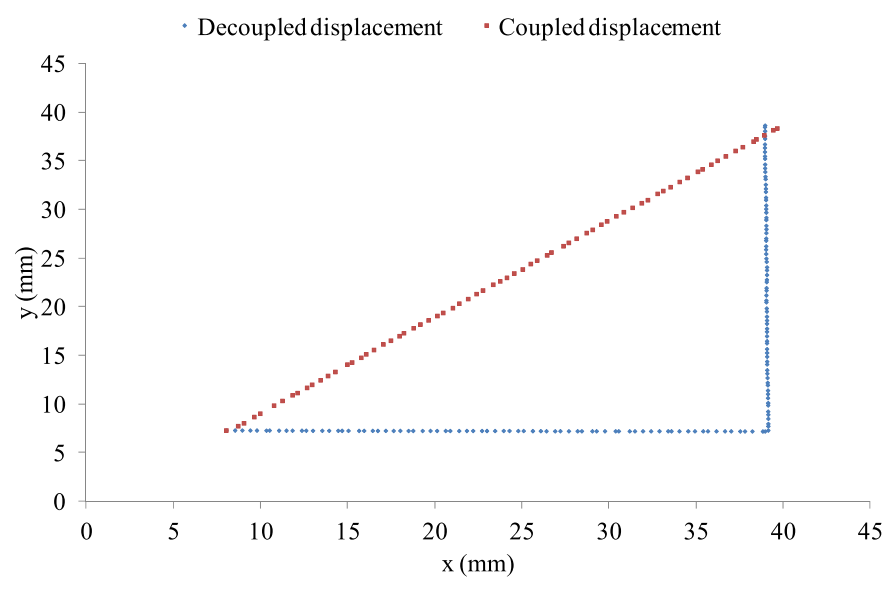

Fig. 17. Coupled and decoupled displacements.

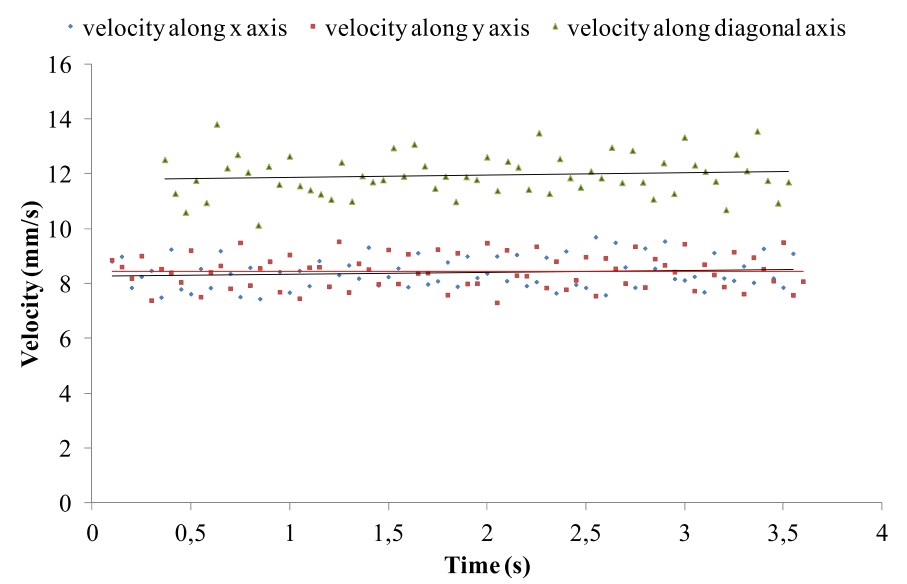

Fig. 18. Velocities for coupled and decoupled displacements.

minimize the number of control signals, it has been decided to only cross two cells in each direction. As the maximum allowable magnitude of the sinusoidal currents injected into coils is $0.8 \mathrm{~A}$, the magnitude of sinusoidal current is $I_{x}=0.4 \mathrm{~A}$ for moving in the $\mathrm{x}$ direction and $I_{y}=0.74 \mathrm{~A}$ for moving in the $\mathrm{y}$ direction. The frequency of these currents for both direction is $f_{x}=f_{y}=4 \mathrm{~Hz}$. Fig. 17 shows the two types of the experimental displacements of the cross structure from cell $(2,2)$ to cell $(3,3)$. The initial position is $\left[x_{0}, y_{0}\right]=[7.3 ; 8.03]$. The final reached positions are respectively $\left[x_{f d} ; y_{f d}\right]=[38.96 ; 38.83]$ for the decoupled displacement and $\left[x_{f c} ; y_{f c}\right]=[39.65 ; 38.33]$ for the coupled displacement (diagonal). The travel time in the decoupled displacement and the coupled displacement is respectively $7.2 \mathrm{~s}$ and $3.73 \mathrm{~s}$. The results demonstrate the possibilities to move in different directions within the conveyance platform. The difference observed for the final position is due to the fact that experiments have been carried out in open loop.

Velocities in both directions are displayed in Fig. 18. For the decoupled displacement, mean velocity is $8.25 \mathrm{~mm} / \mathrm{s}$ for $x$ axis displacement and $8.42 \mathrm{~mm} / \mathrm{s}$ for $y$ axis displacement. The means velocity for the diagonal displacement is obviously $\sqrt{2}$ times higher than the decoupled velocity and is experimentally $11.76 \mathrm{~mm} / \mathrm{s}$.

In the case of coupled displacements, totally, 16 cells are powered while only 8 cells are necessary to be powered in the case of decoupled displacement to perform the displacement from the starting point to the arrival point. In order to estimate the ratio of energy consumption between these two trajectories, the number of supplied coil at each time has been taken into account and show approximately energy consumption two times higher for the coupled displacement.

\subsubsection{Simulation of the experiment setup}

In the emSS model, the electromagnetic forces applied on 2 diametrically opposed extremities of the cross-shaped pallet are considered to be symmetric. That implies that the effect of rotation on the pallet can be neglected and there are no deviations of the direction of a pallet while it moves along one single axis.

Fig. 19 illustrates the HMI of the modeled emSS used by the supervisor for controlling one pallet in open loop. In order to validate the emSS modeling, a first simulation is realized in open loop as in the experimental setup. In this simulation, a pallet is moved in the diagonal direction by supplying currents into the emSS cells with the amplitude of $I_{x}=0.4 \mathrm{~A}, I_{y}=0.74 \mathrm{~A}$ and the frequency of $f_{x}=f_{y}=4 \mathrm{~Hz}$. It moves for a distance of $30 \mathrm{~mm}$ as illustrated in Fig. 20. All design and mechanical characteristics of 


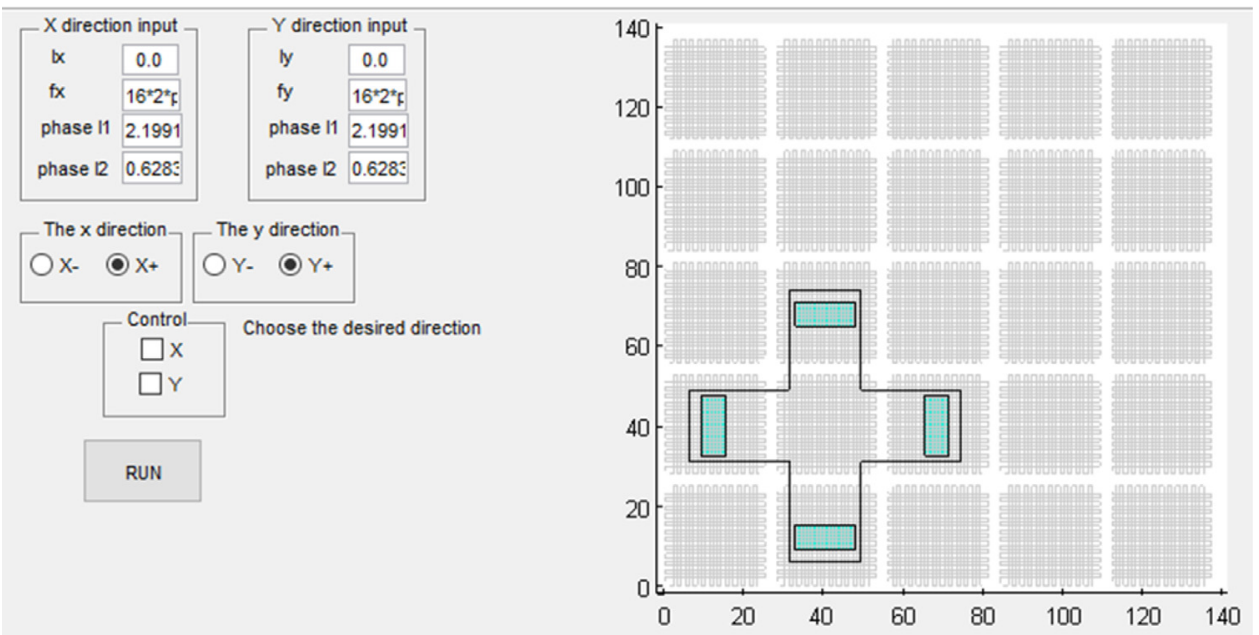

Fig. 19. HMI for manual control of a pallet in open loop.

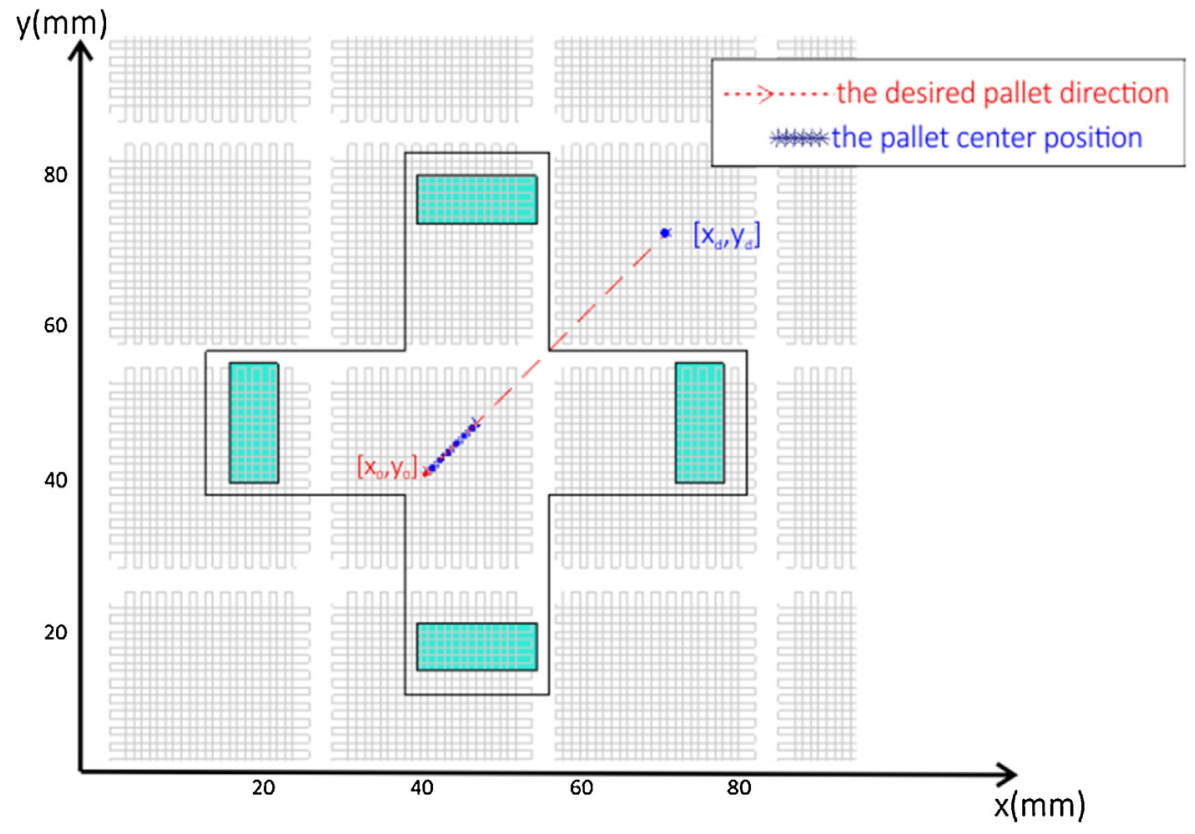

Fig. 20. Pallet displacement in open loop with $f_{x}=f_{y}=4 \mathrm{~Hz}, I_{x}=0.4 \mathrm{~A}, I_{y}=0.74 \mathrm{~A}$.

the emSS such as the air gaps, the adhesion coefficient, etc. are respected in the model.

The simulation shows that the pallet moves in the desired direction and reaches the arrival point at the time of $3.702 \mathrm{~s}$ and it has the same average speed for the $x$ and $y$ components, equals to $8.1 \mathrm{~mm} / \mathrm{s}$. This simulation result is in good agreement with the experimental result. It allows to validate the electromagnetic and mechanical model and enables the simulation of different trajectories. The velocity curves in the $x$ and $y$ directions are shown in Fig. 21. When the pallet crosses the transition zone, the velocity values are dropped as expected. Due to the magnitude difference of current and the air gaps interval, the velocity curves in the $\mathrm{x}$ and $\mathrm{y}$ directions aren't similar.

\subsection{Case 2: Validation of the generation process of the refined trajectory}

As mentioned in the activity A22, the pallet trajectory in the emSS is the curve that links the starting point $\left[x_{0}, y_{0}\right]$ to the arrival point $\left[x_{d}, y_{d}\right]$. In this case study, a given square matrix platform that is partitioned into a uniform grid square cells, is considered as the emSS simulation. As the emSS is a square matrix, the index of each cell will be automatically generated and assigned as the identifier of cell. The "defected" state denotes the occupied areas or failure cells and they are represented in white in the emSS representation as shown in Fig. 22 with their own identifier.

For demonstration purpose, the cell centers correspond to potential via points and a graph is defined for finding a path linking the starting point to the arrival point crossing these via points. The distance between a cell center and its neighbors and the travel time are the operation costs for evaluating the transfer from a point to the others. In the simulation, the Floyd Warshall algorithm [36] is used to find the shortest path via a graph because it is suitable for rapid execution in Matlab while using matrix representation. For simplification, the cost values are calculated in function of the distance. The calculation of pallet path is repeated and tested for different emSS configurations. 


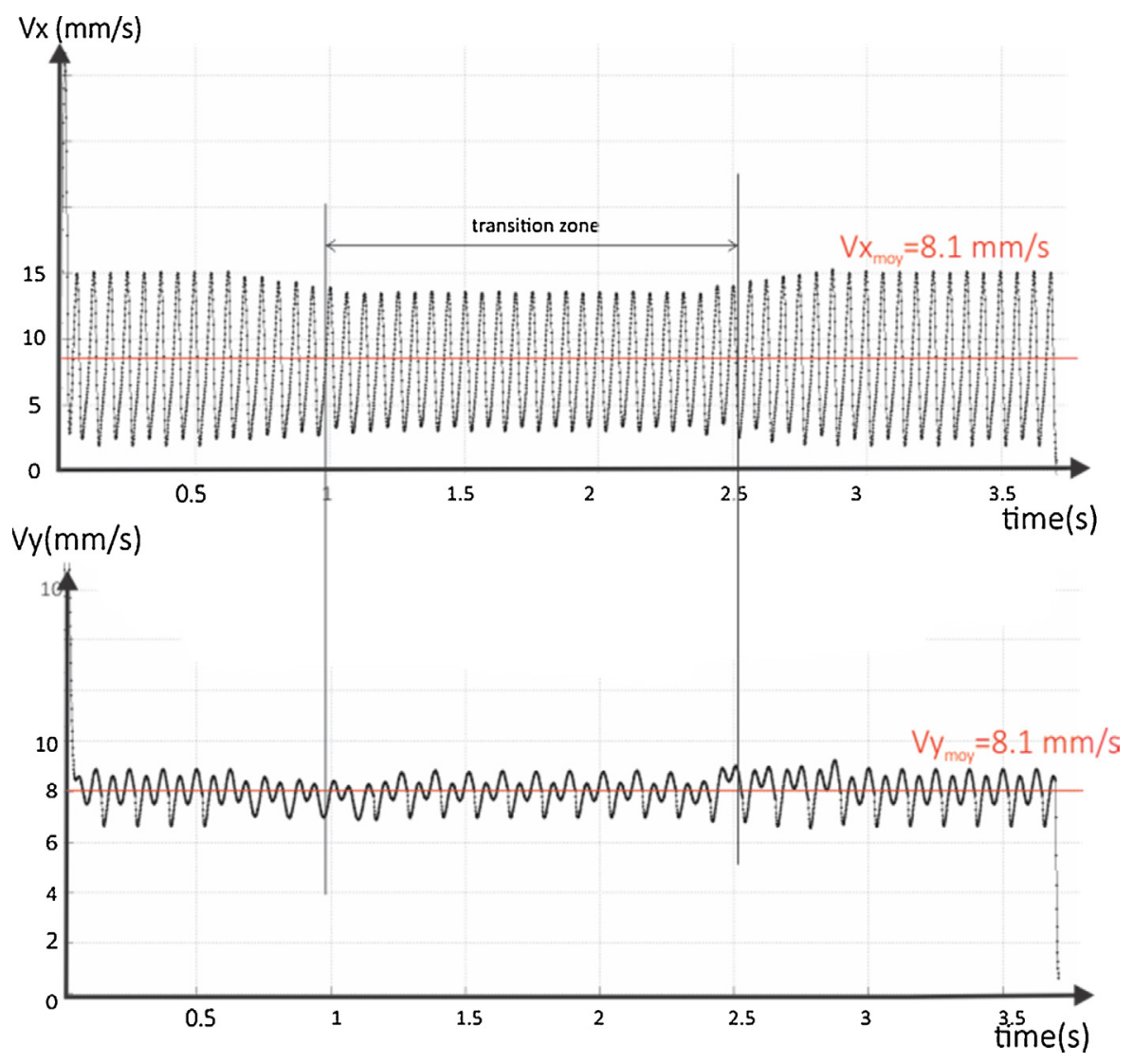

Fig. 21. Variation of velocity in the $x$ and $y$ directions in function of time.

Fig. 22(a) shows the found path that links all the cell centers. In the case where the cell state at the index 20 is defected, the path is kept as the previous case because this cell is not used to move the pallet (Fig. 22(b)). However, when the cell at the index 19 is removed from the emSS (Fig. 22(c)), the algorithm recalculates automatically a new path. Fig. 22(d) shows the recalculated path when the removing of a cell at the index 9 occurs. The use of the graph method for calculating the path allows the flexibility of pallet travels within the emSS since it enables automatic routing reconfiguration.

As the raw trajectory is a list of cells centers, these simulated paths show the possibility to find raw trajectories from the current position to a defined destination. The previous experiment has proven that these trajectories are accessible. In order to optimize the pallet paths, interpolation methods are used to calculate the refined trajectories considering specified constraints such as energy consumption or travel time.

Fig. 23 illustrates the way to smooth the raw trajectories using the interpolation method-Cubic Hermit and then define the refined trajectory. In the future, different interpolation methods will be studied to respond to the specified requirements (for instances: minimize the pallet's stroke or energy consumption, etc.).

\subsection{Case 3: Managing the collision avoidance between 2 pallets}

As mentioned in the previous Section 4.2., path recalculation allows avoiding the cell at "defected" state. The next step is to avoid collisions between pallets. The travel time of a pallet from a workstation to another is defined by production schedule. For simplification, in this case study, the collision avoidance strategy is applied based on the raw trajectory. As explained previously, the raw trajectory is constituted of a set of consecutive segments that link the cell centers. For each segment, a pallet moves in straight line in a travel time $t_{i}(i=1,2, . . n), n$ denotes the number of segments. In order to respect the desired direction, the current frequency needs to be adapted for each segment.

A frequency $f_{i}$ denotes the reference for calculating the frequency in $\mathrm{x}$ and $\mathrm{y}$ direction $\left(f x_{i}, f y_{i}\right)$. This frequency defines the travel time $t_{i}$ to reach the destination and $s_{i}$ denotes the distance that pallet will travel. As the pallet displaces on a planar surface and the pallet speed is related to the frequency of injected currents, to reach the destination at the same time $t_{i}$ in the both $x$ and $y$ direction, the velocity in the $\mathrm{x}$ and $\mathrm{y}$ direction need to be coherent. The velocity in the $x$ direction could be determined in function of the velocity in the y direction and vice versa. Therefore, there are two options for calculating the frequency $f_{i}$ as shown below:

$$
\begin{aligned}
& \text { - } s_{i}=\min \left(\Delta x_{i}, \Delta y_{i}\right) \text { and } f_{i}=\min \left(f x_{i}, f y_{i}\right) \\
& \text { - } s_{i}=\max \left(\Delta x_{i}, \Delta y_{i}\right) \text { and } f_{i}=\max \left(f x_{i}, f y_{i}\right)
\end{aligned}
$$

A pallet moves from $\left[x_{0}, y_{0}\right]$ to $\left[x_{d}, y_{d}\right]$ (Table 3$) . s_{i}=\min (\Delta x$, $\Delta y)=30 \mathrm{~mm}$ and $f_{i}=f x=4 \mathrm{~Hz}$. The travel time is $3.702 \mathrm{~s}$. A program calculates the frequency fy with the smallest error of position, less than $0.06 \mathrm{~mm}$ in this case. The simulation results are shown in Table 3.

As shown in Fig. 24, the variation of the frequency is approximately linear but not perfectly because of the influence of the transition zones number that the pallet crosses over. The results show the possibility to manage the desired direction by defining the corresponding frequency $f_{i}$ for the distance $s_{i}$. 


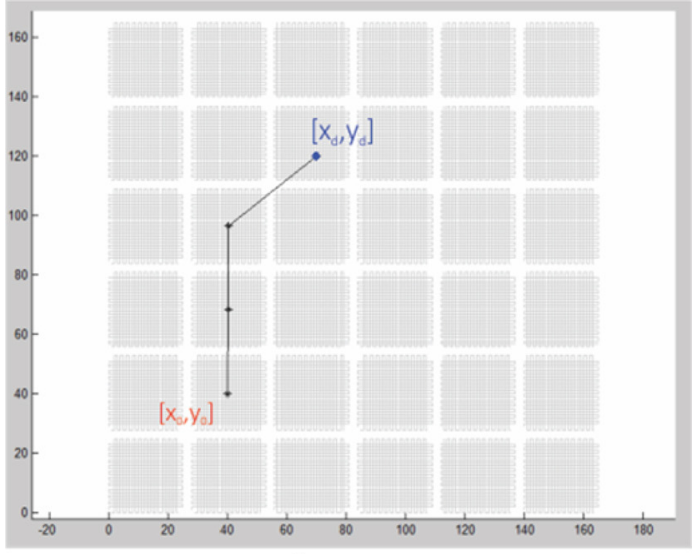

a)

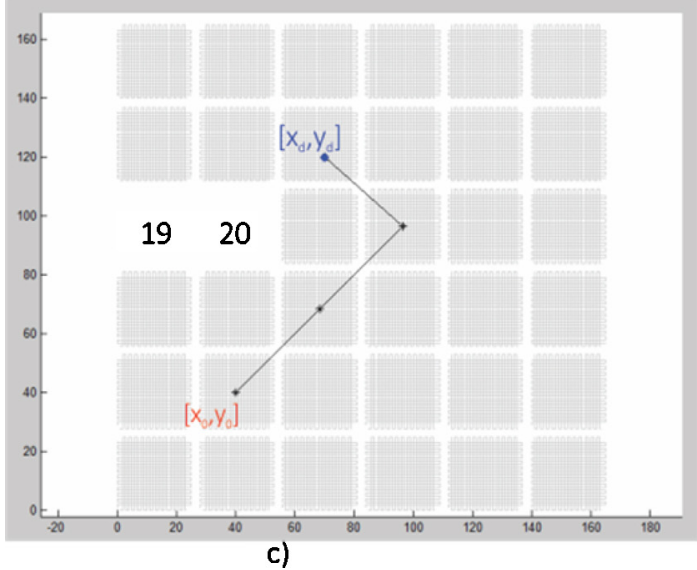

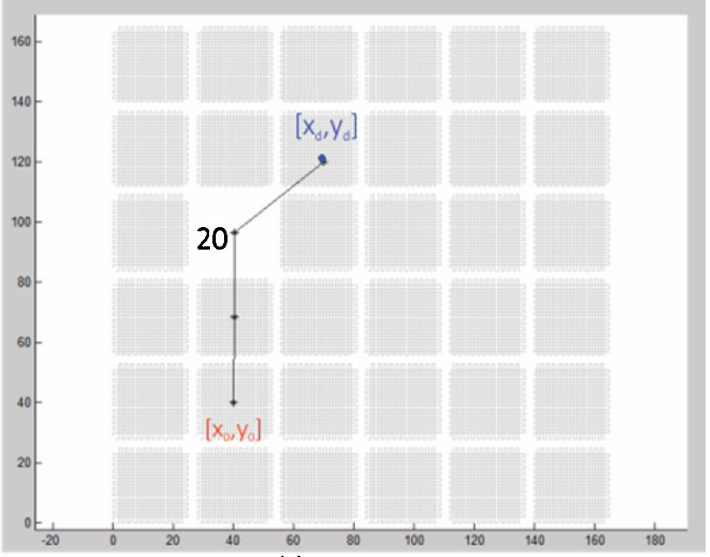

b)

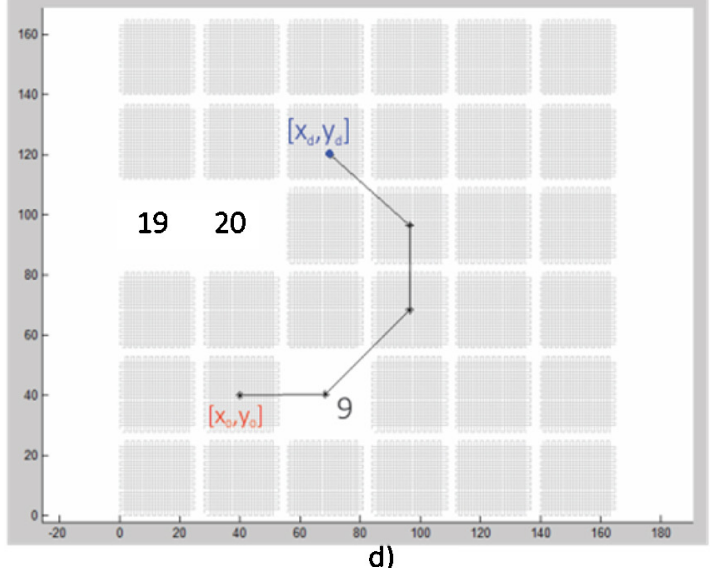

d)

Fig. 22. Calculation of pallet path in different configuration layouts.
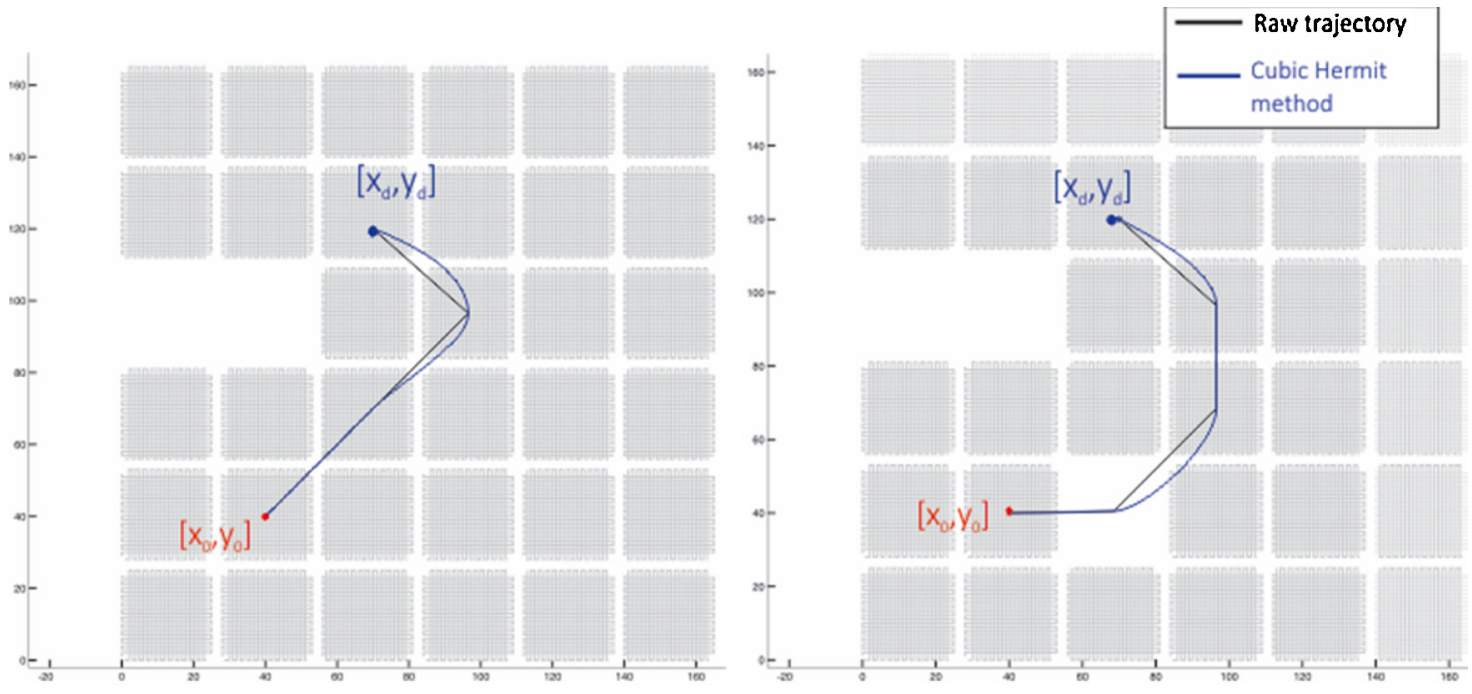

Fig. 23. Refined trajectory with the cubic Hermit method.

For the collision avoidance demonstration, a simulation of two pallets paths is realized. The two pallets $p 1$ and $p 2$ are displaced on the $10 \times 10$ square matrix emSS in straight line as shown in Fig. 25 . The pallet $p 1$ goes from a position $\left[x 1_{0}, y 1_{0}\right]=[40,40] \mathrm{mm}$ to $\left[x 1_{d}, y 1_{d}\right]=[230,230] \mathrm{mm}$ while the pallet $p 2$ moves from $\left[x 2_{0}\right.$, $\left.y 2_{0}\right]=[210,70] \mathrm{mm}$ to $\left[x 2_{d}, y 2_{d}\right]=[40,180] \mathrm{mm}$. In order to control the two pallets along the desired direction, the powered currents to the emSS are shown in Table 4 according to the previously defined rule.

Fig. 25shows the emSS simulation without collision avoidance. The sinusoidal currents are chosen in order to move each pallet in the desired direction from the starting point to the 
Table 3

Simulation results in case of displacement to different destinations in a fixed travel time $t=3.702 \mathrm{~s}$.

\begin{tabular}{llllll}
\hline$\left[x_{0}, y_{0}\right]$ & {$\left[x_{d}, y_{d}\right]$} & $\Delta x(\mathrm{~mm})$ & $\Delta y(\mathrm{~mm})$ & $f_{x}(\mathrm{~Hz})$ & $f_{y}(\mathrm{~Hz})$ \\
\hline$[40,40]$ & {$[70,70]$} & 30 & 30 & 4 & 4 \\
{$[40,40]$} & {$[70,80]$} & 30 & 40 & 4 & 5.4 \\
{$[40,40]$} & {$[70,90]$} & 30 & 50 & 4 & 6.72 \\
{$[40,40]$} & {$[70,100]$} & 30 & 60 & 4 & 8.09 \\
{$[40,40]$} & {$[70,110]$} & 30 & 70 & 4 & 9.45 \\
{$[40,40]$} & {$[70,120]$} & 30 & 80 & 4 & 10.08 \\
\hline
\end{tabular}

\section{Frequency in function of distance}

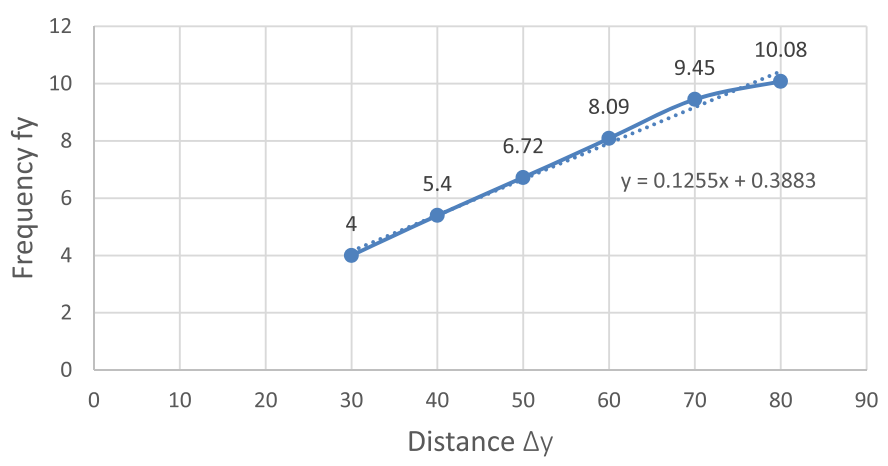

Fig. 24. Calculating the frequency $f_{y}$.
Table 4

The parameters of the sinusoidal currents for moving 2 pallets $p 1$ and $p 2$.

\begin{tabular}{lllll}
\hline Pallet & $I_{x}(\mathrm{~A})$ & $I_{y}(\mathrm{~A})$ & $f_{x}(\mathrm{~Hz})$ & $f_{y}(\mathrm{~Hz})$ \\
\hline$p 1$ & 0.4 & 0.74 & 6 & 6 \\
$p 2$ & 0.4 & 0.74 & 6 & 3.89 \\
\hline
\end{tabular}

defined. As seen in Fig. 25, the pallet $p 2$ is nearer to the point of intersection than the pallet $p 1$, it means that the pallet 2 enters the collision area before the pallet $p 1$. When the pallet $p 1$ reaches the collision area, it gets an instruction that requires the pallet reduces its speed and then stops at a secure position. Hence, the pallet $p 1$ has to wait for pallet 2 leaving the collision area as shown in Fig. 26. During the simulation timeline, four images captured at time $t$ respectively $4.78 \mathrm{~s}, 6.5 \mathrm{~s}, 8.58 \mathrm{~s}$ and $9.63 \mathrm{~s}$ are shown on Fig. 26 and simulated the stop position of the pallet $p 1$ and the on-going of the pallet $p 2$.

Fig. 27 illustrates the displacement of the two pallets during the simulation. There have no collisions of the two pallets at the intersection point. The figure shows the coordinates of the position of the pallet $p 1$ and $p 2$ centers in function of simulation time and it shows the secure distance between two pallets to avoid collision. When the pallet $p 2$ reaches the arrival point, the pallet $p 1$ restarts its displacement. It means that the two pallets are controlled simultaneously and independently. The simulation is stopped at the time of $22.249 \mathrm{~s}$.
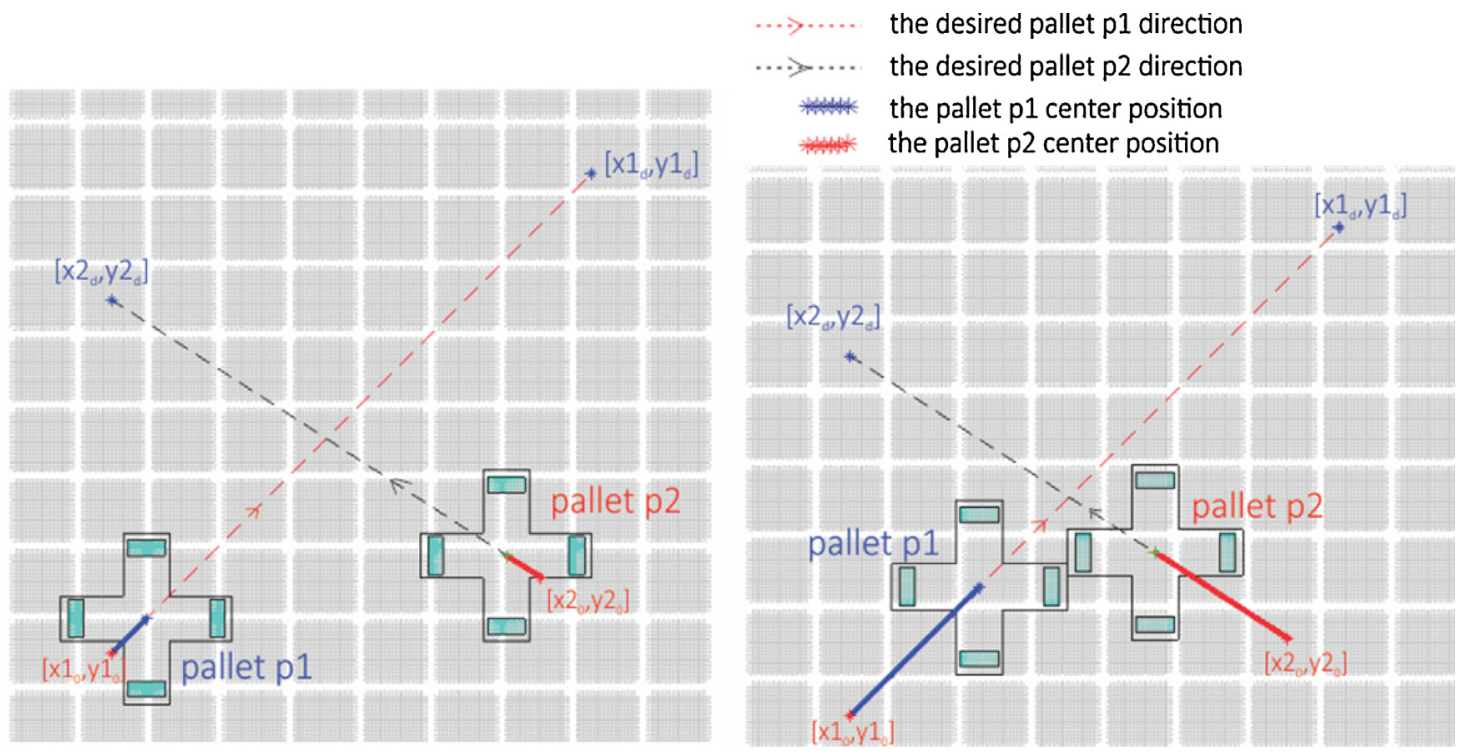

Fig. 25. Controlling 2 pallets in open loop.

arrival point. In this first simulation, the "checking collision" module is not used. With these parameter inputs, when two pallets reach at the same time the point of intersection, a collision is happening.

In order to avoid the collision, a "checking collision" module is implemented. In this case study, three areas are defined just as shown in Fig. 11, including the collision area around the point of intersection and the secured areas of pallet 1 and pallet 2. When two among three areas intersect, a control strategy is
The velocity curve of the pallet $p 1$ (Fig. 28) shows that the pallet $p 1$ reduced its speed before stopping its displacement during a waiting time and restarted with slow speed. Furthermore, the effect of crossing the transition zones is illustrated by small and timely speed magnitude decreases.

In this section, the "monitor and control of the emSS" activity interest has been demonstrated and shows the ability to adapt trajectories in case of defected cells also the possibility to avoid collision. 
T.A.T. Dang et al./Computers in Industry $x x x$ (2016) $x x x-x x x$

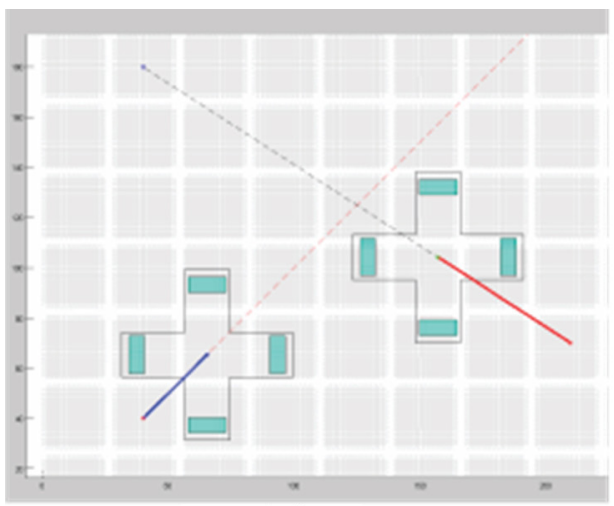

$\mathrm{t}=4.78 \mathrm{~s}$

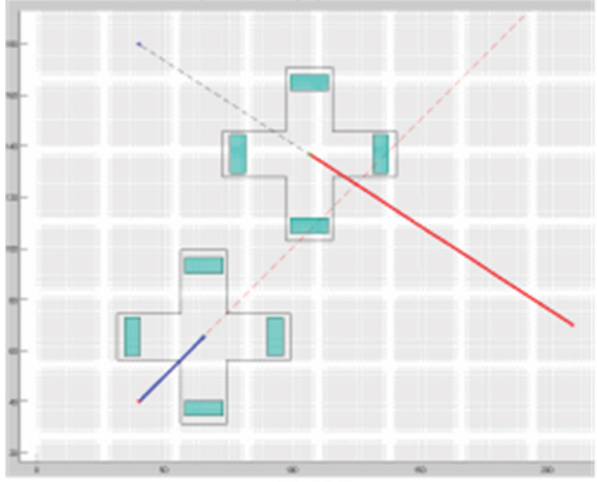

$\mathrm{t}=8.58 \mathrm{~s}$

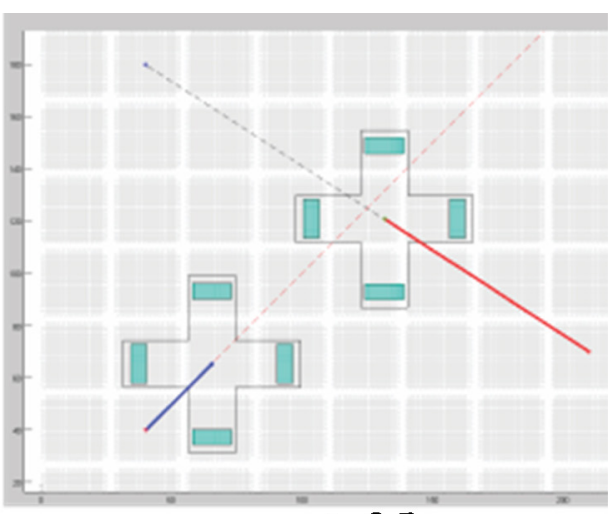

$\mathrm{t}=6.5 \mathrm{~s}$

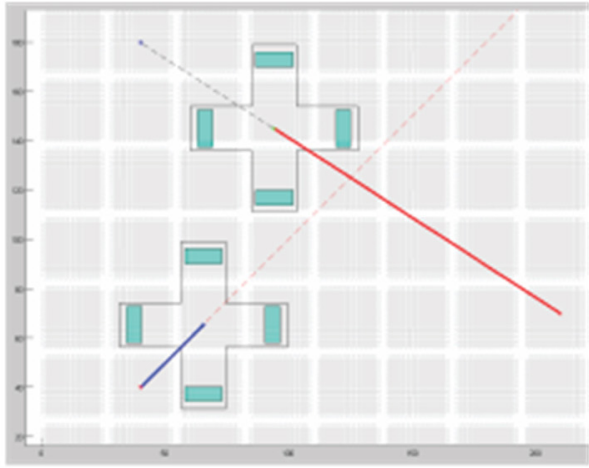

$t=9.63 \mathrm{~s}$

Fig. 26. Pallet positions snapshots at time $t=4.78 \mathrm{~s}, t=6.5 \mathrm{~s}, t=8.58 \mathrm{~s}, t=9.63 \mathrm{~s}$.

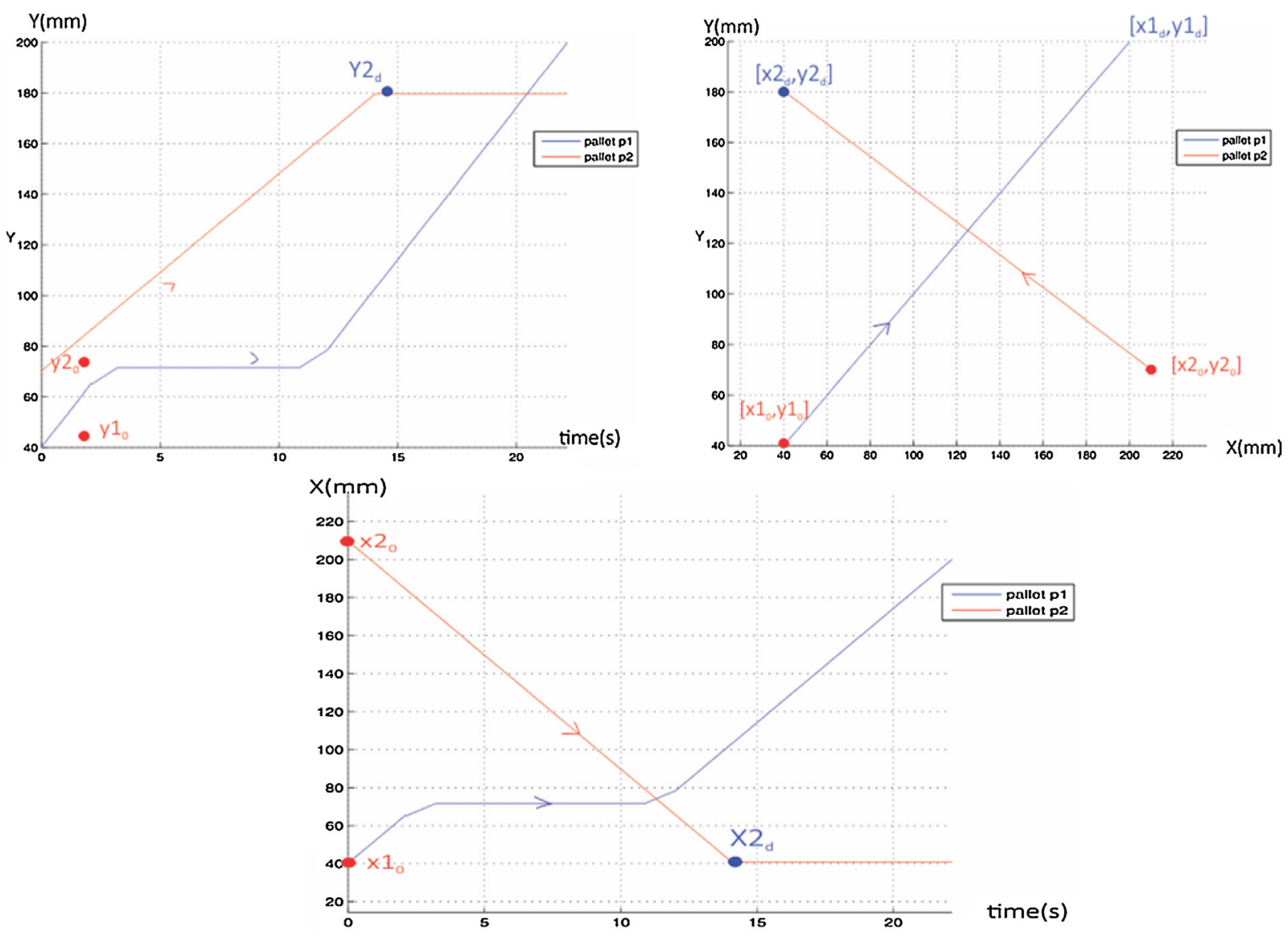

Fig. 27. Displacement trajectory of pallet $p 1$ and $p 2$. 


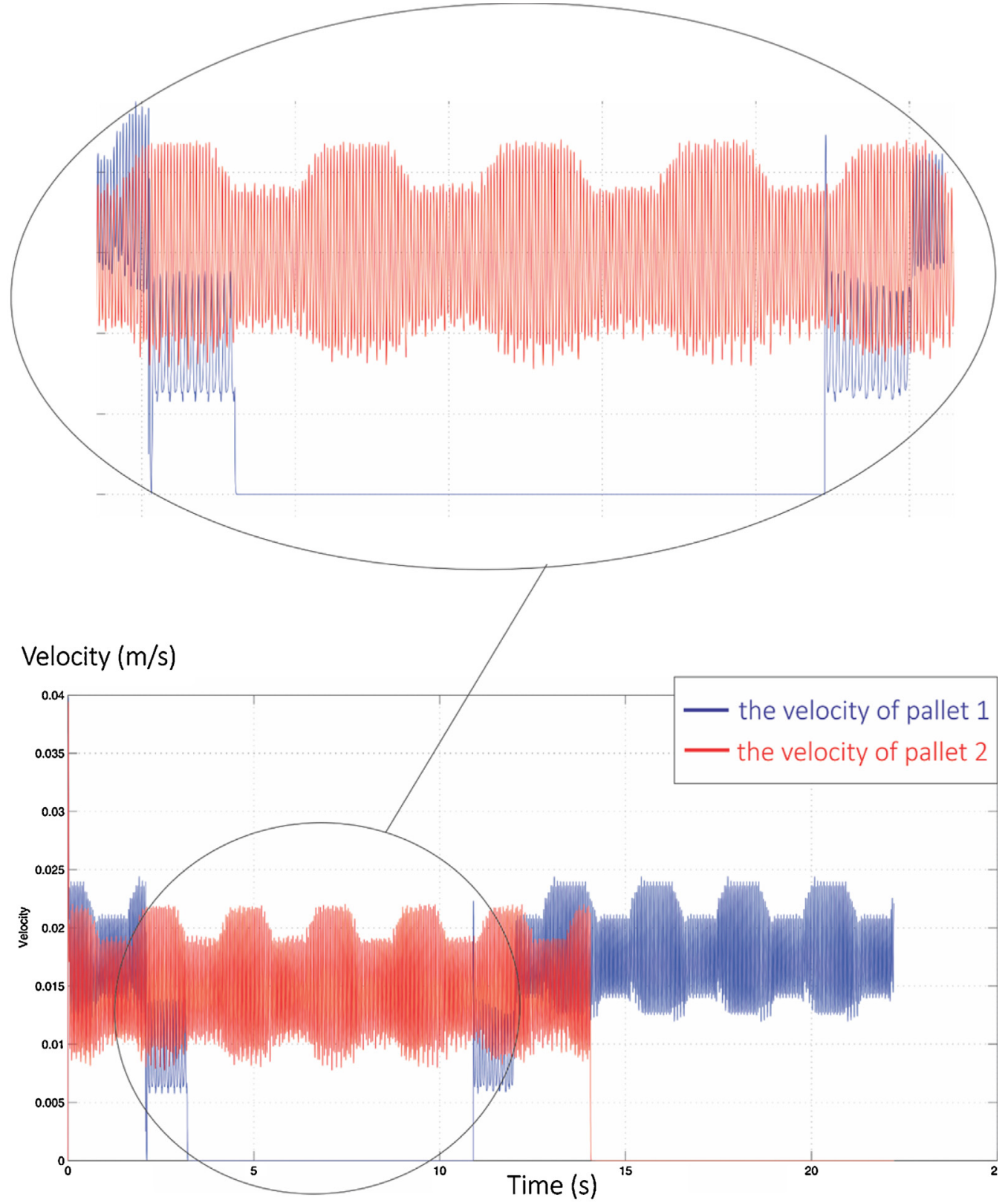

Fig. 28. The velocity of the 2 pallets in function of time.

\section{Conclusion and future works}

This paper presented the technical principle and its associated framework for managing an electromagnetic modular Smart Surface as the transfer unit or conveyance system of a modular microfactory. This paper argued that the proposed emSS is a relevant candidate for the paradigm of reconfigurable micromanufacturing systems. A framework to model and simulate the emSS control is presented. First experimental results show the ability of the proposed framework to perform planar trajectories firstly with decoupled $x$ and $y$ displacements then with coupled displacements. The choice of the desired trajectory depends on the objective: fast displacement or minimal energy consumption. The ability to generate refined path trajectories and to avoid collision is respectively demonstrated by using path-planning algorithms and interpolation methods and by simulation using simple rule for priority definition.
Future works will focus on improving the framework to take into account more complexity in managing pallets and on improving the strategy of trajectories determination. On the technological point of view, a larger emSS will be designed and manufactured to be able to test multi-pallet strategies.

In the future, the collision avoidance strategy could be decided by an autonomous pallet without following a predefined protocol and without needing supervision. In this case, the different cells forming the emSS as well as the pallets could be modeled as agents based systems. All these agents collaborate to reject disturbances (for instances: reduce velocity of a pallet to avoid collision with another, adjust the pallet's trajectory in case of miss target location). The combination of global and local schedulers could improve the performance of the controller. Future framework will include the simulation of production systems to enhance the daily operations and investigate the future alternatives of solutions for decision-making and evaluation. 


\section{Acknowledgements}

This work is a part of the MICROCOSM (Micro-Coordinate Measuring Machine) project. It was funded in the framework of the Conseil de la Région Picardie (2014-2017).

\section{Appendix A. Supplementary data}

Supplementary data associated with this article can be found, in the online version, at http://dx.doi.org/10.1016/j.compind. 2016.02.003.

\section{References}

[1] R. Reichwald, Christof M. Stotko, T.P. Frank, Distributed mini-factory networks as a form of real-time enterprise: concept, flexibility potential and case studies, in: The Practical Real-Time Enterprise, Springer-Verlag, Berlin Heidelberg, 2005, pp. 403-434.

[2] Y. Okazaki, Microfactories-a new methodology for sustainable manufacturing, Int. J. Autom. Technol. 4 (2) (2010) 82-87.

[3] R. Tuokko, R. Heikkilä, E. Järvenpää, A. Nurmi, T. Prusi, N. Sitala, A. Vuola, Micro and Desktop Factory Roadmap, Tampere University of Technology, Department of Production Engeering, Tampere, 2012.

[4] Y. Koren, M. Shpitalni, Design of reconfigurable manufacturing systems, J. Manuf. Syst. 29 (October (4)) (2010) 130-141.

[5] N. Siltala, T. Prusi, A. Vuola, R. Heikkila, R. Tuokko, Modular microfactory system for gas sensor assembly, in: IEEE International Symposium on Assembly and Manufacturing (ISAM), 2011.

[6] S. Scheifele, J. Friedrich, A. Lechler, A. Verl, Flexible, self-configuring control system for a modular production system, in: Second International Conference on System-Integrated Intelligence: Challenges for Product and Production Engineering, 2014, 398-405

[7] N. Kawahara, T. Suto, T. Hirano, Y. Ishikawa, T. Kitahara, N. Ooyama, T. Ataka, Microfactories, Microsyst. Technol. 3 (2) (1997) 37-41.

[8] T. Gaugel, H. Dobler, M. Bengel, C. Weis, J. Schliesser, Building a mini-factory from a technology construction kit, in: In Proc. 3rd Int'l. Workshop on Microfactories, September 16-18, 2002, Minneapolis, MN, (2002), pp. 5-8.

[9] W. Wang, Y. Koren, Scalability planning for reconfigurable manufacturing systems, J. Manuf. Syst. 31 (2012) 83-91.

[10] Koren Y. and Ulsoy A.G., Reconfigurable Manufacturing System having A Production Capacity Method for Designing Same and Method for Changing its Production Capacity, United States Patent, US 6349237 B1, 2002.

[11] Y.-A. Chapuis, Y. Fukuta, Y. Mita, H. Fujita, Autonomous decentralized systems based on distributed controlled mems actuator for micro conveyance application, J. Inst. Ind. Sci. Univ. Tokyo 56 (1) (2004) 109-115.

[12] R. Yahiaoui, R. Zeggari, J. Malapert, J.F. Manceau, A MEMS-based pneumatic micro-conveyor for planar micromanipulation, Mechatronics 22 (2012) 515-552.

[13] K. Boutoustous, G.J. Laurent, E. Dedu, L. Matignon, J. Bourgeois, N. Le Fort-Piat, Distributed control architecture for smart surface, in: Proceedings of the IEEE International Conference on Intelligent Robots and Systems, October 18-22, 2010, Taipei, Taiwan, 2010.

[14] B. Piranda, G. Laurent, J. Bourgeois, C. Clévy, S. Möbesb, N. Fort-Piat, A new concept of planar self-reconfigurable modular robot for conveying microparts, Mechatronics 23 (October (7)) (2013) 906-915.

[15] Y. Okazaki, N. Mishima, K. Ashida, Microfactory and micro machine tools, in: The first Korea-Japan Conference on Positioning Technology, Daejeon, Korea, 2002.

[16] Y. Okazaki, N. Mishima, K. Ashida, Microfactory-concept, history, and developments, J. Manuf. Sci. Eng. 126 (4) (2004) 837-844

[17] K. Ashida, N. Mishima, H. Maekawa, T. Tanikawa, K. Kaneko, M. Tanaka, Development of desktop machining microfactory, in: Proc. J-USA Symposium on Flexible Automation, 2000, 175-178.

[18] R.L. Hollis, J. Gowdy, A.A. Rizzi, Design and Development of a Tabletop Precision Assembly System, Mechatronics and Robotics, September 13-15, 2004, Aachen, Germany, (2004), pp. 1619-1623.

[19] E. Descourvières, S. Debricon, D. Gendreau, P. Lutz, L. Philippe, F. Bouquet, Towards automatic control for microfactories, in: Fifth Int. Conf. on Industrial Automation, June 2007, Montréal, Québec, Canada, 2007.

[20] S. Fatikow, J. Seyfried, Control Architecture of a flexible microrobot based micro assembly, in: Proceedings of the seventh Mediterranean Conference on Control and Automation (MED99), June 28-30, 1999, Haifa, Israel, 1999.

[21] D. Gendreau, M. Gauthier, D. Heriban, P. Lutz, Modular architecture of the microfactories for automatic micro-assembly, J. Rob. Comput. Integr. Manuf. 26 (4) (2010) 354-360.

[22] E. Descourvières, D. Gendreau, P. Lutz, Data representation for the control of full-automated microfactories, in: Proceedinos of the Fifth International Workshop on MicroFactories, Besançon, France, 2006.

[23] M. Bosch-Mauchand, C. Prelle, J. Daaboul, T.A.T. Dang, S.B. Labato, Preliminary contributions of industrial management methods to microfactory context: Case of microfactory conveyors integration, in: Proceedings of Joint Conference on Mechanical, Design Engineering and Advanced Manufacturing, June 18-20, 2014, Toulouse, France, 2014.
[24] E. Descourvières, D. Gendreau, P. Lutz, F. Kiefer, Specification of technical of dedicated to a reorganizable and reconfigurable microfactory, in: Fourth International Workshop on MicroFactories, Shanghai, China, 2004.

[25] H.A. ElMaraghy, Reconfigurable process plans for responsive manufacturing systems, in: Proceedings of the CIRP International Design Enterprise Technology (DET) Conference, 18-20 September, 2006, Setubal, Portugal, 2006.

[26] E. Jarvenpaa, R. Heikkila, R. Tuokko, Logistic and control aspects for flexible and reactive micro and desktop assembly at the factory level, in: Proceedings of 2009 IEEE International Symposium on Assembly and Manufacturing, November 17-20, 2009, Suwon, Korea, 2009.

[27] D. Schmidt, J. Kegeler, 3, MiniProd - Miniaturisiertes Produktionssystem, wtonline, 95, Springer-VDI-Verlag, 2005, pp. 146-149.

[28] D.R.W. Barr, D. Walsh, P. Dudek, A smart surface simulation environment, in: Systems, Man, and Cybernetics (SMC), 2013 IEEE International Conference on, 13-16 Oct. 2013, (2013), pp. 4456-4461.

[29] N. Arora, M.U. Khan, L. Petit, C. Prelle, A planar electromagnetic actuator based on two layer coil assembly for micro applications, in: IEEE/ASME Conference on Advanced Intelligent Mechatronics, July 8-11, 2014, Besançon (France), 2014, 6 pages.

[30] N. Arora, T.A.T. Dang, L. Petit, M. Bosch-Mauchand, J. Daaboul, C. Prelle, Contribution to microfactory technologies: a flexible conveyor and its dedicated control system, in: 9th International Workshop on Microfactories, October 5-8, 2014 Honolulu, U.S.A, 2014.

[31] Y. Fukuta, Y.A. Chapuis, Y. Mita, H. Fujita, Design, fabrication, and control of MEMS-based actuator arrays for air-flow distributed micromanipulation, . Microelectromech. Syst. 15 (4) (2006) 912-926.

[32] H. Nakazawa, Y. Watanabe, O. Morita, M. Edo, E. Yonezawa, The twodimensional micro conveyer: principles and fabrication process of the actuator, in: Proceedings of International Solid State Sensors and Actuators Conference, June 16-19, 1997, Chicago, 1997.

[33] H.P. Wiendahl, H.A. ElMaraghy, P. Nyhuis, M.F. Zäh, Changeable manufacturing-classification, design and operation, CIRP Ann.-Manuf Technol. 56 (2) (2007) 783-809.

[34] M.U. Khan, N. Bencheikh, C. Prelle, F. Lamarque, T. Beutel, S. Büttgenbach, A long stroke electromagnetic XY positioning stage for micro applications, IEEE/ ASME Trans. Mechatron. 17 (5) (2012) 866-875.

[35] M.U. Khan, N. Bencheikh, C. Prelle, F. Lamarque, T. Beutel, S. Buttgenbach, Silicon conveyor based electromagnetic device for linear displacement (July 2010), in: IEEE/ASME International Conference Advanced Intelligent mechatronics Association Information and Management, Vol. no. 2, Montreal, QC, Canada, 2010.

[36] R.K. Ahuja, T.L. Magnanti, J.B. Orlin, Network Flows Theory, Algorithms, and Applications, Prentice Hall, Upper Saddle River, NJ, 1993p. 07458.

[37] R.H. Heikkila, I.T. Karjalainen, J.J. Uusitalo, A.S. Vuola, R.O. Tuokko, Possibilities of a Microfactory in the Assembly of Small Parts and Products-First Results of the M4-project, in: International Symposium on Assembly and Manufacturing, Proceedings of the 2007 IEEE, July 22-25, 2007, Ann Arbor, Michigan, USA, 2007.

[38] O. Klemd, Desktop factory-new approaches for lean micro assembly, in: International Symposium on Assembly and Manufacturing, ISAM, 2225.07.2007, Ann Arbor, Michigan, USA, (2007), pp. 161-165.

[39] S. Nakano, K. Ashida, J. Akedo, On Demand Manufacturing System, a Solution of Ecological MEMS Factory, in: Sixth International Workshop on Microfactories IWMF 2008, Northwestern University, October 5-7, 2008, Evanston, Illinois, USA, 2008, pp. 73-76.

[40] A.A. Rizzi, J. Gowdy, R.L. Hollis, Distributed coordination in modular precision assembly systems, Int. J. Rob. Res. 20 (10) (2001) 819-838.

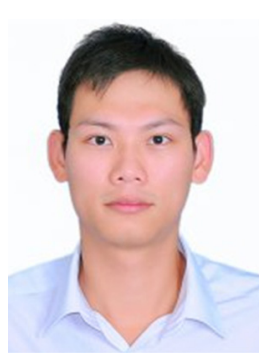

The Anh Tuan DANG received his Master's degree in "Advanced Systems and Robotics" from UPMC, Paris 6 , France in 2013 and his engineer's degree in Industrial Engineering from Polytech Lyon, Villeurbanne, France in 2012. He is currently working toward the Ph.D. degree in a microfactory project at the Roberval Laboratory, Université de Technologie de Compiègne, France.

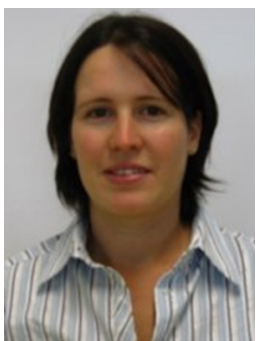

Magali BOSCH-MAUCHAND received her PhD in Mechanical Engineering from the University of Nantes and Ecole Centrale de Nantes in 2007 on the modelling for the simulation of value creation chains in industrial enterprise as a decision-making aid tool in the product design and production engineering phases. She is Assistant Professor in Department of Mechanical Systems Engineering of the Université de Technologie de Compiègne-UTC (France). She is also member of UMR UTC/CNRS 7337 Roberval. Her research topics focus on Product Lifecycle Management, Production Process Management and Digital Manufacturing. 


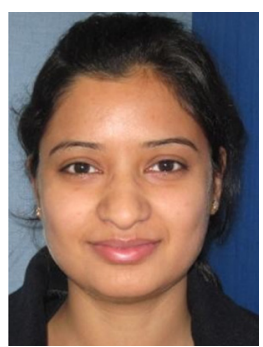

Neha ARORA received the Bachelor of Engineering degree in instrumentation and controls engineering from the Maharshi Dayanand University in Haryana, India. In 2010, she received her Master's degree in mechanic and systems with specialisation in mechatronic systems from the Université de Technologie de Compiègne-UTC (France). She is currently working toward the Ph.D. degree in mechanical engineering at the Université de Technologie de Compiègne, France.

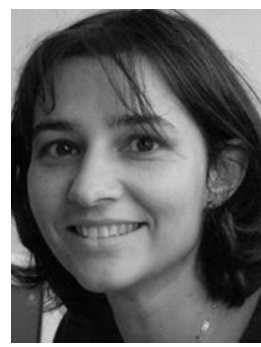

Christine PRELLE received the Ph.D. degree in industrial automatic control from Institut National des Sciences Appliquées Lyon, Villeurbanne, France, in 1997. She is a Professor in control engineering and mechatronics at Université de Technologie de Compiègne, Compiègne, France. She is currently in charge of the emergent research team "Integrated Systems in Mechanics" at Roberval laboratory of Université de Technologie de Compiègne. Her research interest focuses on micromechatronics and control.

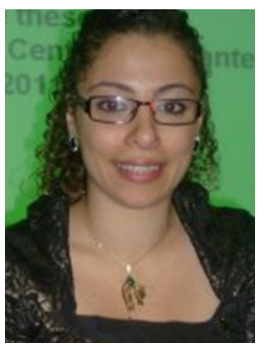

Joanna DAABOUL is Assistant Professor at Université de Technologie de Compiègne and researcher in Roberval Mechanical Laboratory (UMR CNRS 7337). She obtained her $\mathrm{PhD}$ in Mechanical Engineering from Centrale Nantes in 2011. Her main research topics are Enterprise Modeling, Systems Performance evaluation, Product/ Process integration, and Mass Customization. 